This is the peer reviewed version of the following article: Shapira, M. and Priestley, M. (2020), Do schools matter? An exploration of the determinants of lower secondary school subject choices under the Scottish Curriculum for Excellence. Review of Education, 8: 191-238, which has been published in final form at https://doi.org/10.1002/rev3.3180. This article may be used for non-commercial purposes in accordance with Wiley Terms and Conditions for self-archiving.

\title{
Do schools matter? An exploration of the determinants of lower secondary school subject choices under the Scottish Curriculum for Excellence ${ }^{1}$.
} Marina Shapira ${ }^{23}$ and Mark Priestley ${ }^{4}$

\section{Abstract}

This paper explores school level determinants of curriculum narrowing in the senior phase of secondary education, under the Scottish Curriculum for Excellence (CfE). It presents findings from an analysis of longitudinal administrative education data (2011-2017), and Scottish Qualifications Authority (SQA) data on subject enrolments for Scottish Credit and Qualifications Framework National 5 level qualifications, undertaken by 14-15-year-old students in year 4 of secondary education (S4) in Scotland. The data are aggregated at the level of schools and linked with Scottish School Census data that provides information about school characteristics (in terms of their size, number of qualified teachers, socio-economic composition, etc.) and school area characteristics. We used descriptive methods of statistical data analysis and multilevel regression modelling, in order to explore the variations between schools in: (a) number of subject choices; and (b) configuration of subject enrolment and to identify factors responsible for these variations.

Our findings show that the senior phase curriculum is becoming narrower. There is trend since 2013, the year when new qualifications under CfE were introduced, for fewer subjects to be taken in school year S4 for level 5 National Qualifications. Yet, the size of this reduction has not been uniform, but has varied between schools of different characteristics, between areas with different level of deprivation and between local authorities across Scotland.

The findings show that the SES composition of school intake has a strong association with the number and configuration of subject entries. A larger reduction in the number of subject entries for National 5 level qualifications took place in schools in more deprived areas, as well as in schools with a larger number of students from disadvantaged socio-economic backgrounds, schools where the proportion of pupils with additional learning support needs was higher, and schools with poorer staff-student ratios. We also found that the number of subject entries was smaller in schools where the overall number of subjects offered for National 5 level qualifications was smaller. Furthermore, we found that schools in areas of higher deprivation and schools with larger numbers of pupils from disadvantaged backgrounds had smaller proportions of young people enrolled in Sciences and Modern Languages, and a larger proportion of pupils enrolled in Vocational subjects.

Key words: Curriculum Narrowing, Subject choice, School characteristics, Scottish Curriculum, Curriculum for Excellence, Multilevel analysis

\footnotetext{
${ }^{1}$ A version of this paper was accepted for publication by Review of Education

${ }^{2}$ University of Stirling

${ }^{3}$ Please address all correspondence to marina.shapira@stir.ac.uk

${ }^{4}$ University of Stirling
} 


\section{Preface}

In September 2018, one of the authors of this paper visited the Martiros Saryan (Britannica) Memorial Museum in Yerevan, Armenia. Despite not being widely known in the West, Saryan is one of the most remarkable painters of the $20^{\text {th }}$ century and the founder of the Armenian national school of modern painting. He was born in 1880 in the provincial town of Nakhichevan in the South of the Russian Empire. In Nakhichevan, he attended secondary school (four-year college), from which he graduated at age 15, to be accepted, two years later, into the Moscow School of Arts. Among a score of personal items and artefacts lovingly preserved and displayed in the Museum was Saryan's secondary school certificate, with the list of subjects he studied and the grades he achieved (see Appendix 4). It immediately caught her attention. Just a day before leaving for Armenia, the same author spent few hours in the Scottish Parliament, giving evidence to the Education and Skills Committee on the reduction in the number of subjects that 15-16 years old in Scotland study for their first National Qualification exams, by the end of the compulsory stage of secondary education under the Scottish Curriculum for Excellence (CfE). 'Is it a bad thing,' she was asked, by the Committee Members, 'that our youngsters study fewer subjects?' In discussions that followed, some argued that a flexibility under CfE, in relation to subject choice, allowed young people to focus on fewer subjects and study them in depth, and subsequently to get better grades at their exams. Yet, apparently, it did not occur to those who governed secondary education in $19^{\text {th }}$ century Russia that the breadth of secondary education should be sacrificed for better exam results Saryan's secondary education certificate evidenced that at age fifteen he studied and was assessed in at least thirteen subjects, among which were Religion, Russian and Old Russian, Arithmetic, Geometry, Natural Sciences (which encompassed Physiology, Botanic, Zoology and Minerology), Physics, History, Geography, Arts, Music, Technical Drawing, Physical Education and Armenian Language. The same author's own secondary school certificate, obtained almost a century later in Armenia, still provides a very similar list of subjects (total number around fifteen). Conversations with our university colleagues, who went to school in the UK during the 1970 s and 1980s, revealed that they also studied a similar range of subjects, with a number of subjects exceeding by far the average subject enrolment number for National 5 level qualifications in Scotland in 2017 (around 6). It seems bizarre to suggest that fifteen year old students nowadays are less capable of studying a broad range of subjects successfully than their counterparts 30, 40 or 123 years ago.

With this in mind, the present paper opens a series of papers that will present findings from our study on understanding the contemporary trends in subject choice at 15, and the relationships between the number and configuration of subject choice and a number of outcomes, such as attainment at age 16 and 18 and early destinations of school leavers in Scotland. The present paper is focused on the school level determinants of the number of subject enrolments across National Qualifications at SCQF level 5 in Secondary schools in Scotland.

\section{Introduction}

In 2004, the Scottish Executive, set out a rationale to justify the change of direction represented by its new Curriculum for Excellence (CfE). These included:

- more space in the curriculum for work in depth, and to ensure that young people develop the literacy, numeracy and other essential skills and knowledge they will need for life and work

- more space for sport, music, dance, drama, art, learning about health, sustainable development and enterprise, and other activities that broaden the life experiences - and life chances - of young people

- more skills-for-work options for young people, robustly assessed and helping them to progress into further qualifications or work (Scottish Executive, 2004, p.4) 
The abovementioned goals suggest a breadth of study through the new curriculum, continuing a tradition of strongly valuing breadth and flexibility in Scottish secondary education (SOED, 1992; Raffe, Howieson \& Tinklin, 2007; Paterson, 2015); a tradition that in particular extended breadth well into the senior phase of secondary education, in comparison with England, Wales and Northern Ireland, where the senior A-Level curriculum has been traditionally less broad. Under CfE, breadth is a clearly mandated feature of the Broad General Education (BGE) phase of secondary education in secondary years 1-3 (S1-S3), although anecdotal evidence (in the absence of robust research in this area) suggests that for many schools, this phase of education has remained largely unchanged since the introduction of CfE. Thus, the BGE phase in many secondary schools remains framed around a number of subjects, often taught as a preparation for the senior phase, rather than as a foundational stage of education, as intended by CfE policy. Additionally, evidence suggests that the BGE has not broadened as a consequence of CfE, there has been a curricular narrowing, with a widespread reduction of choice in many secondary schools in the early part of the senior phase, in year S4. This has occurred uniformly in all schools within some local authorities (e.g. Scott, 2015; Shapira \& Priestley, 2018). In particular, there has been a notable reduction in both the numbers and proportion of students taking Modern Languages and Arts for their qualifications at levels 4-6 of Scottish Credit Framework (SCQF). The evidence indicates that this trend might disproportionally be affecting students with low socio-economic status (Shapira \& Priestley, 2018).

The narrowing of the curriculum in S4 has been highly controversial in Scotland. The controversy has been stoked by extensive media coverage, which has at times assumed the proportions of a moral panic, talking in polemical terms of the 'crisis' that is 'putting the education of a generation of pupils at risk', and which has spread like 'a virus' (The Herald, 2019. Also see: Times Educational Supplement, 2018; The Scotsman, 2019). Conversely, proponents of the new narrower S4 curriculum have claimed that the number of subjects in S4 is not an issue; what counts is the breadth of the curriculum over the full range of the S4-6 senior phase, and the number of qualifications with which a student leaves school (e.g. see: BBC, 2014). As with the policy intentions to broaden the BGE in secondary schools, this senior phase flexibility is intended to promote breadth; however, anecdotal evidence again suggests that there is a gap between policy intentions and school curricular practices. Very few schools have taken advantage of this flexibility, and the prevailing pattern seems to be to continue to treat the SCQF as a ladder of qualifications, with progression from level to level and a general expectation that level 5 qualifications are a prerequisite for future study at a higher level in a particular subject. Therefore, curriculum narrowing in S4 may have significant effects on future enrolment and transitions, by narrowing subsequent choice; while it is theoretically possible for students to mix and match qualifications across the whole senior phase, in practice such opportunities seem to be more limited. As with the BGE, further research is needed to explore these patterns of provision, and their effects on subsequent enrolment, transitions and attainment.

This heated public debate has become a high-stakes political issue for the governing Scottish National Party, and a putative test of both their competence in education and the credibility of CfE as a flagship policy. The media storm has been largely fuelled by some fairly superficial analysis of publicly available qualifications statistics and data obtained from local authorities via freedom of information requests (e.g. Scott, 2015; Reform Scotland, 2019). These analyses indeed confirm that there is a pattern of narrowing in S4, and have led to an ongoing (at the time of writing) inquiry by the Education and Skills Committee of the Scottish Parliament ${ }^{5}$. However, they leave unaddressed some important questions too; the changing patterns of curriculum provision and the phenomenon of curriculum narrowing manifesting in the reduction of subject entries made in Senior Phase of secondary education, as well as their underlying causes, are currently not well understood, due to a lack of systematic and fine-grained research, especially that aggregated at the level of students and schools. Questions relate to the nature and extent of curriculum narrowing (i.e. choice and enrolment), its associations with issues such as social equity (e.g. whether it differentially affects some populations more than others), and the consequences of narrowing at this stage on subsequent attainment

${ }^{5}$ https://www.parliament.scot/parliamentarybusiness/CurrentCommittees/110962.aspx 
and transitions. This paper seeks to address the first and to some extent second sets of questions; fuller analysis of the second set and addressing of the third set will follow in subsequent papers.

Secondary curriculum narrowing is not a purely Scottish phenomenon but reflects more universal trends across the UK. In media articles following the annual release of examination results in August 2018, for example, similar trends of a decrease in number of subject choices in upper secondary stages of education, as well as a considerable decline in numbers of young people who study Modern Languages and Arts for their secondary qualifications, were evidenced in England (The Guardian, 2017; The Guardian, 2018; Telegraph, 2018). Yet, the reasons for the Scottish curriculum narrowing are peculiar to Scotland. It is to an extent linked to developments within - and can even be seen as an unintended consequence of - CfE itself. These developments include: (a) the introduction of new national qualifications at levels 4 and 5 in the Scottish Credit and Qualifications Framework (SCQF) from 2013, which were designed to be consonant with the new curriculum; and (b) the increasing flexibility of the secondary education system, insofar as Local authorities and schools can now decide how many subjects they offer to S3/S4 students for levels 4 and 5 qualifications in the Scottish Credit and Qualifications Framework. The former issue is especially significant, as CfE replaced two year certificated courses with qualifications taken in one year, without reducing the amount of time (160 hours) required for study. To avoid reducing the number of qualifications taken, schools must either reduce the time allocated to each subject or engage in creative solutions (for example covering content in the final S3 year of the BGE). For a fuller overview of these contextual issues, readers should refer to Shapira and Priestley (2018).

Existing research evidence highlights the importance of qualifications in the upper tier of compulsory secondary education (at age 14 and 15), both for subsequent attainment at ages 16-18 and for the transitions of young people from secondary education into positive destinations and their future carrier (lannelli \& Smyth, 2017; Chevalier, 2011; Dolton \& Vignoles, 2002; Dolton at al. 2003; Altonji et al. 2012). Yet, subject choices are seldom determined by students' individual preferences and academic abilities alone. There is a link between curriculum choices and the family background of young people (e.g. Klein, lannelli, Smyth \& Klein 2016; Henderson et al., 2018; lannelli \& Duta, 2018). There is also a link between the social and ability compositions of school intake and subject choices of pupils (e.g. Anders et al., 2018). Moreover, school characteristics affect subject choices too and, even after accounting for family background and academic ability, young people who attend schools with higher proportions of pupils from disadvantaged socioeconomic background are less likely to select academic subjects than those who attend schools with more advantageous social composition of their intake (e.g. Marks, 2015; Anders et al., 2018).

Existing research shows that the link between family socio-economic background and secondary education outcomes is stronger in education systems that allow lesser standardisation and a greater degree of flexibility and choice (e.g. Ayalon \& Gamoran, 2000; Bol et al., 2014), such as the Scottish one. It can be expected that the role of the school, as a moderator between a pupil's background and their outcomes, is also more important in such education systems. Ideally, schools should be able to compensate for disadvantages linked to family background, through offering extra resources and support to those students who need them most. Indeed, research shows that school characteristics are more important for the attainment of students from less advantageous socio-economic and ethnic backgrounds (e.g. Shapira, 2012). Similarly, it might be expected that schools play a greater role in the subject choices of young people coming from the lower SES families. While students from more advantageous backgrounds might receive informed advice at home on subject choices, students from disadvantageous backgrounds mostly rely on schools for such an advice. Young people could be deliberately steered by teachers into choosing fewer subjects and less academic subjects, based on the teacher's subjective perceptions about their abilities and potential to pass exams and, for young people from disadvantaged backgrounds, such steering would be less likely to be counterbalanced by an alternative opinion from their family. It might be expected, then, that under a regime of a greater autonomy and choice, bestowed on schools under CfE, a school's decision to offer certain subjects/certain number of subjects to all or some pupils would be shaped by school resources, characteristics of schools such as staffing issues (e.g. a 
lack of teachers in some subject areas), as well as by the social and ability compositions of school's intake, etc. Furthermore, such decisions are likely to be influenced by the output regulation of schools (for example evaluative use of qualifications data to judge the effectiveness of schools); such high stakes accountability has been linked with the development of highly performative cultures in many schools (e.g. see: Keddie et al., 2011; Priestley, 2015). Given the importance of curriculum choices made at 15 (Iannelli \& Duta, 2018), it is necessary to understand the current trends in subject choices, the way CfE has impacted these choices, and the extent to which this impact varies across schools of different characteristics, and between pupils from different socio-economic backgrounds.

The overall aim of this study is to contribute to the understanding of ways in which the new Scottish curriculum has affected the number and configuration of subject entries made by young people in secondary year 4 (S4) of their secondary education, when they take subjects for National 5 level qualifications, and to explore the above individual (school) level factors that affect the subject choices.

The aim of the study is met through addressing the following research questions:

1. Is there evidence of the senior phase curriculum narrowing over the period of the introduction of CfE?

2. Is there evidence of changes in the configuration of subject choices over the period of the introduction of CfE?

3. What are the relationships between the number of subject choices and school characteristics?

4. Is there evidence that the relationships between the number of subject choices and school characteristics have changed over the period of the introduction of CfE?

5. What are the relationships between the configurations of subject choice and school characteristics?

6. Has the relationships between the configurations of subject choice and school characteristics changed over the period of the introduction of CFE?

The study uses administrative data provided by Scottish Government, combining Scottish Qualification Authority (SQA) data on subject enrolment and attainment at SCQF levels 3-7, and School Census data, aggregated by secondary schools in Scotland, for years 2011-2017.

In the sections that follow, we first provide an overview of the context, and then outline our approach to analysing the data, and present our findings. 


\section{Background and context}

\section{Curriculum choice and social mobility}

In Scotland, as in the rest of the UK, there is no standardised certification system in which students need to take a certain number of compulsory subjects to complete secondary education and qualify for entry in the $\mathrm{HE}$. There is also no formal selection and tracking into academic versus vocational subjects. In Scotland young people are offered a University place based on a combination of their achievements and subject choices (e.g. lannelli, Smyth \& Klein, 2016), with a particular focus on level 6 Higher qualifications, typically taken in the fifth year of secondary education. There is evidence that, in loosely stratified and loosely standardised education systems without formal selection and tracking and without standardised certification, such as the Scottish education system (Raffe \& Howieson, 1999), curriculum decisions and choices replace formal tracking and either facilitate or hinder school leavers' transitions into Higher Education (Playford \& Gayle, 2016; lannelli and Smyth, 2017). Good grades are important for securing a university place, but subject choice plays a particularly strong role in accessing prestigious (e.g. Russell group) universities, with those young people who studied 'facilitating' subjects (i.e. English, Maths, Science and Language subjects) and achieved good grades in these subjects having good chances of being accepted to these universities (e.g. lannelli, Smyth \& Klein, 2016). Yet, the selection of school subjects within the secondary systems in Scotland and elsewhere in the UK is socially patterned; there are differences in subject uptake by parental social class and the social inequalities in subject choice in S3/S4 are also reproduced in S5/S6 (Playford et al., 2016; lannelli, Smyth \& Klein, 2016).

While students from more advantaged socio-economic backgrounds rely on their family resources and receive informed advice on the choice of subjects such as Maths, English, Sciences and Modern languages, that facilitate their admission into prestigious universities (lannelli, 2013), pupils from disadvantaged socioeconomic backgrounds are more likely to make choices at 14-15 that may adversely affect the configuration of their subject choices at age $16-17$, by selecting 'easy' (often vocational) subjects ${ }^{6}$ rather than academic subjects that would enable their transition in Higher Education (ibid.). Research evidence also suggests that young people from lower socio-economic background are being actively channelled into subject choices (including 'easy' vocational subjects) that would not facilitate their successful transition from school to Higher Education. Through this channelling, curriculum choices do not just reflect but also exacerbate existing social inequalities (Henderson et al., 2018). Indeed, subject choice as early as at age 14-15 determines: (1) subject choice for Higher (level 6) qualifications; 2) whether young people would be able to make a transition into higher education; and (3) to what type of educational institutions they are likely to be admitted (e.g. lannelli \& Duta, 2018). Curriculum choices at age 15 are also linked to social class destinations, for example low skilled occupations in later life (ibid).

\section{School level predictors of subject choices}

Findings from existing research show that individual and family level characteristics of young people, such as their aptitude (approximated by prior attainment), their family socioeconomic background, and their gender are all associated with the subjects they study at age 14-16 (Henderson et al. 2018). For example, prior

\footnotetext{
${ }^{6}$ Although we make the observation that vocational subjects are often considered to be 'easier', and thus low attaining students are likely to be channelled into taking them, we take the view that diversification at 14 is beneficial for many students, and that vocational subjects are not inferior to academic subjects. Full discussion of this issue is beyond the scope of this paper, which instead explores patterns of provision, choice and enrolment in relation is issues such as SES.

${ }^{7}$ Officially, choices are made at the end of the third secondary school year (S3), although anecdotal evidence suggests that some decisions are required as early as the end of S1 (age 12-13).
} 
attainment is positively associated with taking academic or facilitating subjects and is negatively associated with taking applied or vocational subjects. The strong link between prior attainment and subject choices suggests that students are channelled into particular subjects based on their prior academic achievements. Yet, parental socio-economic background is linked strongly to the choice of subjects at age 14-15 and this association remains strong even when prior attainment is accounted for. For example, although the impact of social class on choosing STEM subjects decreases after accounting for the impact of prior attainment, youngsters from disadvantaged socio-economic backgrounds are still less likely to select STEM subjects and more likely select vocational subjects than their peers from higher socio-economic background, with a similar prior attainment (Henderson et al. 2018).

Despite the importance of individual level differences, such as prior attainment, gender and social class in determining the subject choice, there is growing evidence about the impact of school on subject choice. There is evidence that different schools increasingly provide different curricula. The curriculum offered by a school is affected by that school's characteristics, such as school composition in terms of number/proportion of students from disadvantaged socio-economic background and/or number/proportion of students with additional needs for learning support (Marks, 2015; Perry \& McConney, 2010; Coleman et al., 1966; Smith et al., 1989; Willms, 1986). Yet, the mechanisms that link school composition and subject choices is not easy to establish empirically, and it is not entirely clear how exactly the former affects the latter. It is possible that schools with students from less advantageous social backgrounds offer young people a number and composition of subject choices that they deem appropriate for them, namely 'easy' vocational subjects (e.g. lannelli \& Duta 2016). Schools, which on average do not perform well on attainment, might decide that a more limited subject choice will increase chances of young people to do well in exams, and thus might reduce the number of subject choices to boost the school's overall performance. The socio-economic composition of schools has also been found to be linked to their ability to retain highly qualified staff (Lupton, 2005; Lupton \& Thrupp, 2012; Ofsted, 2013), which in turn affects the range of subjects that schools offer. Yet, Marks (2015) suggests that school socio-economic composition does not have a direct effect on individual academic performance, but simply reflects the fact that students from lower SES tend to perform overall less well academically. Other researchers point out that, in schools where many students are low attaining, their disruptive behaviour adversely affects the performance of other students. It has been long claimed that school composition influences both teachers and curriculum, since teachers adjust their pedagogical style to low attainers and set low requirements and expectations for all students (Woods, 1976).

In their recent study, Anders and colleagues (2018) highlighted the role that schools play in many subject choice decisions. They suggested that schools' actions are often strongly associated with school characteristics, such as the composition of school intake in terms of academic attainment and socio-economic status of pupils' families, which impose constraints on what schools can viably offered by schools (ibid). Thus, they found a strong association between the SES composition of school and subjects studied: for an individual student the impact of the school SES on their subject choice was as strong as the impact of their family SES (ibid). Overall, school level covariates explain about a third of the variation in academic selectivity of subjects; pupils in schools with more socio-economically and academically advantaged intakes are more likely to study more academically selective subjects, even after controlling for individuals' own SES (ibid). Similarly, the overall level of academic attainment at school was also found to be positively linked to choice of more academic subjects, after accounting for young people's prior attainment and family background, while the odds of studying any applied subjects is negatively linked to an overall level of school's academic attainment. In their attempt to uncover the mechanism that links between school's SES and subject choices, Anders and colleagues (2018) suggested that schools may deliberately take into account SES composition and offer young people subjects that they deem appropriate for them (ibid). Secondly, given the known difficulty that schools with a high intake of children from lower SES have in recruiting and retaining highly qualified staff (Lupton, 2005; Lupton \& Thrupp, 2012; Ofsted, 2013), they suggested that a lack of qualified staff in shortage areas 
such as sciences and modern languages place constraints on the number and composition of subjects offered to young people. These findings suggest that the expression 'subject choices' should be used with caution, because they are often extremely limited.

\section{Subject choice under CfE}

In Scotland, existing research evidence on curriculum choices mainly refers to the period under the 'old' Scottish school curriculum (e.g. Iannelli 2013; lanelli \& Duta 2018; lannelli, Smyth \& Klein, 2016; Playford et al. 2016). Within CfE, curriculum design varies according to local authority. Some local authorities ensure standardisation by prescribing a fixed model for all secondary schools, whereas others delegate decisions to schools. This variation, however, should not obscure the general trend towards curriculum narrowing, which owes more to the national level factors identified in this paper; even in local authorities with standardised approaches, the number of subjects being taught for National Qualifications correlates with factors such as socio-economic status of a school (Shapira \& Priestley, 2018). The emphasis of the Scottish CfE on flexibility, greater choice and individualisation of learning might be perceived as a positive feature of the new curriculum, but greater choice might have a number of unintended consequences. Currently, there are only two compulsory subjects in S3/S4 (Maths and English) and no compulsory subjects in S5 and S6 in Scotland. Whereas previously 8 subjects was the norm for the first tier of National Qualifications, many schools now offer as few as 5 or 6 subjects for the National 4/National 5 examinations (e.g. Priestley \& Shapira 2018; Scott 2015). Students/parents and teachers/schools can decide not only on a number of subjects, but also on the level of qualification and the configuration of subjects offered and enrolled for National 3-5 qualifications.

More standardised and rigid school curricula protect students from misinformed or uninformed subject choice, by making sure that all students seek qualifications in several compulsory subjects that facilitate their successful transition from secondary education into tertiary education and work. We are not advocating a restriction of students' choice to 'traditional' subjects. On the contrary, we are pointing out at the importance of choice and breadth at a key point in young people's education, including vocational and non-traditional options. Young people at age 15 often select subjects without sufficient knowledge about the consequences of their choice (e.g. lannelli \& Smyth, 2017). If the number of subjects to select is limited to five or six subject (two of which, Maths and English, are compulsory ones) then some subjects might not be selected because they are deemed difficult or boring, or both. Under the Scottish CfE, school practices that allow young people not to select such subjects as sciences, social sciences, arts and modern languages, and/or which actively divert students whom teachers do not think are capable, from taking too many/particular subject choices, or which do not offer them an option to select some of these subjects due to a limited number of subjects offered by the school. Yet, research evidence shows both nationally and internationally, limited subject choice can be detrimental for young people's prospects of entering $\mathrm{HE}$ institutions and finding a good job, especially those from disadvantaged backgrounds (e.g. Dilnot, 2018; lannelli and Duta, 2018; Chmielewski, 2017). Limited choice in S4 may also limit subsequent choice at school, for example by restricting the choice of Highers subsequently available.

Given the emphasis within CfE on school autonomy, on flexibility and individualisation in terms of subject choice, it might be expected that the secondary curriculum would become more diversified across the schools in Scotland, with schools' decisions in relation to curriculum being increasingly linked to school characteristics such as social class and ability composition of school's intake, staffing issues, etc. As a result, additional, school-level constraints for individual subject choices of pupils are increasingly imposed, with schools making decisions not only about the subjects they can offer based on their teaching resources, but also based on what they deem suitable. Since students from disadvantaged SES backgrounds are overconcentrated in schools in deprived areas and in schools that underperform academically, it might be 
expected that this increased school autonomy in relation to the curriculum decisions would increase the link between young people family background and subject choice.

\section{Hypotheses}

Given the above considerations about the consequences of the greater school autonomy, curriculum flexibility and individualisation for subject choice, we hypothesise the introduction of the qualifications designed for CfE in the senior stage of secondary education has led to:

Hypothesis 1: Increased variation in the number and configuration of subject choices for SCQF National 5 level qualifications across schools, local authorities and regions in Scotland.

Hypothesis2: Increased dependency between school characteristics and the number and configuration of subject choices:

H2.1. Schools in more deprived areas and schools with larger number of students from disadvantaged socio-economic backgrounds experienced a faster decline in the number of subject entries for National 5 qualifications than schools in more advantageous areas and schools with a smaller proportion of students from low socio-economic backgrounds.

H2.2 Schools with staffing problems experienced a faster decline in number of subject entries for National 5 qualifications than schools that are adequately staffed.

H2.3 Schools that offer a smaller range of subjects for National 5 qualifications have on average fewer subject entries per student at this level of qualifications.

H2.3. Schools in more deprived area and schools with a larger number of students from disadvantaged socio-economic backgrounds experienced a faster decline in the number of student entries in academic/facilitating subjects and a faster increase in the number of student entries in vocational subjects than schools in more advantageous areas/schools with a smaller proportion of students from low socio-economic backgrounds.

\section{Methodology}

\section{Data.}

As discussed in the literature review section, there are many factors, acting above the level of individual students selecting subjects for their qualifications, that constrain subject choices. Quantitative inquiry based on the administrative data that records final subject entries made by young people cannot determine the extent to which these entries reflect the initial preferences and choices of young people. Yet, it is reasonable to suggest that these final entries (in terms of both their number and a configuration) present a combination of individual preferences and the constrains on these preferences placed by schools. Therefore, in this study we operationalise 'subject choices' as number of subject entries for National 5 level qualification made by a young person in $\mathrm{S} 4$ in a state funded secondary school in Scotland.

In this study we used administrative data on subject enrolment, attainment and school leavers' destination for all secondary schools in Scotland , provided by the Scottish Government. The dataset comprises the following data: 
A. SQA enrolment and attainment statistics data for years 2010/11-2016/17 (aggregated by secondary schools in Scotland): (https://www.sqa.org.uk/sqa/48269.8311.html). The SQA attainment statistics provide information for pupils on:

1. The number of entries of pupils at SCQF levels 3 to 7 for every subject and overall.

2. The number of pupils entered in every subject at stages of secondary school (S4-S6)

3. The number of pupils entered in every subject at different levels of the SCQF (level 3 - level 7).

4. The number of passes (i.e. number of pupils achieving grades $A$ to $C$ ) for every subject and overall at different levels of the SCQF.

B. Scottish Government data on attainment and transitions in the National Statistics School-Leaver Destinations Survey and the Follow-Up School-Leaver Destinations Survey data (2009-onwards) has information on pupils' destinations three and nine months after they have left (publicly-funded) schools in Scotland. The data are aggregated at the level of secondary schools.

C. Scottish Pupil Census data that provides information about pupils and schools (such as school size), number of qualified teachers, demographic and socio-economic characteristics of the school intake and characteristics of the school's local area (such as the deprivation level of a school's postcode area, using the Scottish Index of Multiple deprivation (SIMD), the rural/urban indicator of school's area, and the local authority indicator).

In this study we used the data on enrolment and attainment (dataset A) merged with the Scottish school Census data (dataset C) for all state-funded secondary schools in Scotland (363 in total). Pre- 2014 entries in Intermediate 2 and Standard Grade Credit level were coded as entries to National 5 level qualifications; pre2014 entries in Intermidiate1 and Standard Grade General level were coded as entries to National 4 level qualifications (see Table A5.1 in Appendix 5, which shows the definitions of levels of study used by Scottish Government).

\section{Variables}

The units of analysis are 363 secondary schools (Level 1 ) in Scotland in 32 local authorities (Level 2) during the period 2011-2017.

Dependent variables:

In this study we focus on the subjects/qualifications entered at SCQF levels 5 (see Table A5.1), aggregated at the level of secondary schools in Scotland:

1) the average number of subject choices per student (at school level) at SCQF level 5;

2) and seven variables that represent the percentage of total entries in each of the 7 subject groups (see Table A1.1 in Appendix1): English, Maths, Sciences, Social Sciences, Modern Languages, Arts and Vocational subjects.

Independent variables:

Our independent variables are school-level characteristics, and the indicator of the time of subject entries (i.e. year 2011-2017).

School characteristics are school enrolment, year \$4 enrolment, teacher-student ratio, number of students in receipt of free school meals (as an indicator of students which families are on low income), percentage of students with additional learning needs, percentage of students from black and minority ethnic backgrounds, a school postcode area's deprivation decile (based on the Scottish Index of Multiple Deprivation), a school's local authority and the urban-rural indicator of local authority . 
The indicator of the time of subject entries was first introduced as a seven category variable (with one category for every year in the period under consideration, 2011-2017) and then as a three category variable, with the categories reflecting the stages of the CfE implementation in Senior secondary phase (1.2011-2013: prior to full introduction of the new National 3-5 qualifications; 2. 2014-year when the new qualifications were first fully introduced and 3. 2015-2017: the period that followed the introduction of new qualifications.)

In order to assess the impact of the introduction of new qualifications under the CfE on subject entries and the configuration of these entries, we use as a comparison group a cohort of young people who studied in year 4 in secondary schools in Scotland and have been enrolling for SCQE National 5 level qualifications during 2011-2013 (i.e. the period prior to the introduction of new qualifications); we compare the number and configuration of subject entries made by this cohort with those made by the subsequent cohorts of students, entering level qualifications after the introduction of new qualifications, in 2014 and during 2015-2017.

Detailed information on dependent and independent variables and their operationalisation is presented in Table 1.

\section{Statistical Method.}

The statistical data analysis was conducted using Stata 14 (StataCorp, 2015) software.

We used descriptive methods of statistical data analysis and regression modelling in order to explore the variations between schools in: (a) number of subject entries; and (b) configurations of subject enrolment, and to identify factors responsible for these variations.

Since schools in our study are nested in local authorities, the number and composition of subject choices are affected not only by the characteristic of students and schools, but also by characteristics of local authorities (for example, they might be affected by educational decisions made at local authority level). Therefore, we used multilevel linear regressions to model the effect of the independent variables on the dependent variables and to explore whether:

1. the variance in number of subject entries and their configurations is partitioned between local authorities and within-Local authorities (i.e. between schools within the same local authority);

2. and the effects of (a) the year of introduction of new qualifications under CfE and (b) the level of deprivation of a school postcode area on the number and configurations of subject entries vary between and within local authorities .

This approach allows accounting for similarities in the school level variables that result from schools' clustering in local authorities and then to examine between-local-authorities variance, to discover which part of this variance can be accounted for by school characteristics, and which part of the variance is attributed to local authority level factors.

Ordinary Least Square regression model with fixed parameters is formulated as:

$$
y=\beta_{0}+\beta_{1} x_{1}+\ldots+\beta_{N} x_{N}+u+e
$$

where $y$ is the dependent variable $a, \beta_{0}$ the intercept, $x_{1 \ldots} x_{N}$ are the independent variables and $\beta_{0} \ldots \beta_{N}$ are the regression coefficients.

Since we assume that there are differences in the values of the dependent variable (e.g. the number of subject choices), not only between level 1 units (schools, in this study), but also from one level 2 unit to another (i.e. from one local authority to another), we use a 2-level mixed random effects linear model: 


$$
(y)_{i j}=\beta_{0}+\beta_{1}\left(x_{1}\right)_{i j}+\ldots+\beta_{N}\left(x_{N}\right)_{i j}+u_{i}+e_{i j}
$$

Here i represents level 2 , local authorities $(1<=i<=32)$, and $\mathrm{j}$ represents schools $(1<=\mathrm{j}<=363)$.

In the random intercept model, the intercept is different across level 2 units (local authorities), but the slopes of each independent variable are the same for each local authority.

In the random intercept and random slopes model, not only intercepts but also slopes of some (or all) independent variables are allowed to vary across level 2 units.

Thus, for example, if we believe that subject entries are different from school to school and from local authority to local authority, and the trends in the reduction of the number of subject entries are different across different local authorities, we can formulate the following random slope and random intercept model:

$$
\text { (subject_entries })_{\mathrm{ij}}=\underbrace{\beta_{0}+\beta_{1}(\text { year })_{\mathrm{ij}}}_{\begin{array}{c}
\text { fixed } \\
\text { part }
\end{array}}+\underbrace{\mathrm{u}_{0 \mathrm{j}}+\mathrm{u}_{1 \mathrm{j}}(\text { year })_{\mathrm{ij}}+\mathrm{e}_{\mathrm{ij}}}_{\begin{array}{c}
\text { random } \\
\text { part }
\end{array}}
$$

where $u_{0 i}$ is and $u_{1 i}$ are random departures or 'residuals' on local authority level from $\beta_{0}$ and $\beta_{1}$ and show how much the line for local authority $j$ is deferent is different from the average line both in its slope and its intercept (Rasbash et al. 2002), $\mathrm{u}_{0 \mathrm{i}}$ and $\mathrm{u}_{1 \mathrm{j}}$ are normally distributed and with mean 0 and covariance matrix [? ${ }_{u}$ with the elements:

$$
\begin{aligned}
& \operatorname{var}\left(u_{0 j}\right)=\sigma^{2}{ }_{u 0}-\text { the variance of intercepts across the mean values }\left(\beta_{0) ;}\right. \\
& \operatorname{var}\left(u_{1 j}\right)=\sigma^{2}{ }_{u 1}-\text { the variance of slopes across the mean values }\left(\beta_{1}\right) \text { and } \\
& \operatorname{cov}\left(u_{0 j}, u_{1 j}\right)=\sigma^{2}{ }_{u 01} \text { - the local authority level intercept/slope covariance. }
\end{aligned}
$$

Finally $e_{i j}$ is the residual, the model's error that shows how much subject choices of school ' $j$ ' within a local authority (i) depart from its local authority average.

$$
\operatorname{var}\left(e_{i j}\right)=\sigma^{2} e_{i j} \text {-the variance of the residual. }
$$

Since this study is carried out on the entire research population (all publicly funded secondary schools in Scotland), the results of the data analysis reflect true population parameters, therefore we do not discuss statistical significance of our findings. However, the standard errors of estimated regression coefficients and variances are presented for the sake of completeness. 
Results.

\section{Descriptive statistics.}

\section{General trends in subject entries}

The main variables in the study are summarised in Table $2 \mathrm{a}$, Table $2 \mathrm{~b}$ and Table $2 \mathrm{c}$ and Figure 1.

Table $2 \mathrm{a}$ in about here

The average number of subject per student entered for National 5 qualifications (in S4) decreased over the period 2011-2014. The first drop in the number of entries took place in 2014 (from an average 7.3 for year 2011-2013 to 5.5 in 2014) and then there was further drop from 5.5 to an average 5.13 for years 2015-2017. Yet, the overall number/range of qualifications available at schools for National 5 level qualifications in S4 remained relatively stable (20-21 qualifications per school) over the period, increasing on average from 20 in 2011 to 21 in 2017.

The sizes of total school roll and S4 roll decreased over the years (from 838.1 and 156.2 respectively in 2011 to 793.2 and 140.3 in 2017), and the number of qualified full time teachers at schools decreased on average from 69 in 2011 to 64.6 in 2017, however, given the corresponding decrease in the sizes of school rolls over the same period, the teacher/student ratio remained unchanged (about 1 teacher per 10 students) (see Table 2a).

Table $2 b$ is about here

Table $2 \mathrm{~b}$ presents trends in number of entries per subject group. The number of entries declined for all subject groups over the period 2011-2014. The first drop in number of entries took place in in 2014, and its size varied between subjects groups; the smallest decrease was around one fifth to one quarter for such subjects as English, Sciences and Vocational Subjects; for Maths enrolments the decrease was about one third, while the number of entries in Modern Languages decreased almost by a half (from 100 in 2011 to 51.6 in 2014). This was followed by another (though considerably smaller) decrease in the number of entries between 2014 and 2015 with a further stabilisation of number of entries per subject group over the period 2015-2017, for all subjects but Modern Languages. For Modern Languages the decrease in the number of entries started before 2014 and continued until 2017.

\section{Table $2 \mathrm{c}$ is about here}

Trends in the configuration of subject entries presented in Table $2 c$ show that the proportions of entries in all subject groups, except Modern Languages and to a smaller degree Arts, remained relatively stable over the period 2011-2017. Thus, percentage of entries (out of total number of S4 entries in National 5 qualifications) into English, Maths, Sciences, Social Sciences and Vocational subjects slightly increased, while the percentage of entries in Art subjects slightly decreased. Yet the proportion of entries in Modern Languages dropped almost by half between 2011 and 2017 .

Figure 1 is about here

Variations in the reduction of subject enrolment across schools and local authorities

There were variations in the trends described above, between schools, across local authorities and across areas with different levels of deprivation (see Figures 2 to Figure 6). Figure 2 shows variation in trends in number of subject entries between school in areas with different level of deprivation (measured by the school postcode area's SIMD decile, with decile 1 representing the most deprived areas) and by local authorities. 
Although the overall trend is one of a decline, there are variations in the rate of the decline across schools in areas with different levels of deprivation. Figure 2.1 shows that in 2011 the variation in the number of subject entries across schools in areas with different levels of deprivation was small - the number of subject entries was closely clustered around the mean value (7.3 subject choices). Yet, already in 2011 there were some variations in number of subject entries by the school area's level of deprivation - it was 8 on average for schools in the SIMD deciles 10, 9 and 8 (i.e. the top three least deprived deciles), but around 7 for the most deprived areas (SIMD deciles 1 to 4). Although on average the number of subject entries has since decreased, the decline was slower in areas with low levels of deprivation and faster in areas with a higher level of deprivation. As a result, in 2017 the variation in number of subject entries between schools in areas with different levels of deprivation became much larger than in 2011. Thus, in 2017 schools in the least deprived areas (SIMD decile 10) had on average seven subjects taken in S4 for National 5 qualifications, while some schools in the most deprived areas (SIMD decile 1) had only five.

There were also variations in trends of decline in the number of subject entries between local authorities, with schools in some local authorities having experienced much faster decline (e.g. Dundee City, Inverclyde) than others (e.g. East Dunbartonshire, Dumfries and Galloway) (Figure 2.2).

Figure 2 is about here

The over-time trends in total number of subjects for National 5 qualification do not seem to be differentiated by schools' area level of deprivation (Figure 3.1). Yet, over-time changes in total number of subjects offered by schools for this level of qualifications varied between different local authorities. As a result, in 2017 the variation in the total number of subjects available in schools between local authorities became larger than in 2011 (Figure 3.2).

Figure 3 is about here

Figures $4 \mathrm{a}$ and $4 \mathrm{~b}$ present trends in a configuration of subject entries for schools in different local authorities and schools in areas with different levels of deprivation. For every school, the configuration of subject entries is represented through a percentage of entries in (a relative intake of) a particular subject group (see Appendix 1) out of total number of subject entries made for National 5 level qualifications in S4. Over the period 20112017, the percentage of English entries, Maths entries and Science entries slightly increased (see Table 2c). Yet, for the English and Mathematics subject areas these were almost undifferentiated, both by local authorities, and by the level of deprivation of schools' local areas. The over-time increase in a relative intake of Science subjects was more differentiated by the level of deprivation of a school's postcode area. Thus, schools in SIMD decile 10 (the least deprived areas) experienced the greatest increase in the proportion of entries in Science subjects (from $21 \%$ in 2011 to $24 \%$ in 2017), while in Decile 1 the proportion of Science entries changed from 16\% in 2001 to $17 \%$ in 2017 (see Figure 4a).

Figure $4 a$ is about here

Figure $4 \mathrm{~b}$ shows trends in relative subject intakes for National 5 qualifications in Social Subjects, Arts, Modern Languages and Vocational Subjects. The trends in Social Subjects' relative intake resemble that of the Maths' and English. The proportion of entries in Social Subjects increased over time slightly, however, there is no a clear pattern of differences in the rate of the increase, neither between schools in different local authorities, nor between schools in areas with different level of deprivation. Over the period of 2011-2017, the proportion of entries in Modern Languages and Arts decreased.

The decrease in the proportion of entries in Modern Languages was very substantial, on average from $8.5 \%$ in 2011 to $4.8 \%$ in 2017 . The rate of the decline was rather similar across local authorities, but the decline was slower in areas of low deprivation. Thus, in SIMD deciles 9 and 10 (the two least deprived deciles), the 
percentage of entries in Modern Languages decreased from 9.2\% in 2011 to 6\% in 2017. In the three most deprived deciles (deciles 1-3) the over-time reduction in the proportion of entries in Modern Languages was $50 \%$ (from $8 \%$ in 2011 to $4 \%$ in 2017).

For Art subjects the decrease was smaller than for Modern Languages. The decrease was rather uniform both across local authorities and across areas with different levels of deprivation.

Finally, trends in the enrolment in vocational subjects resemble those in Sciences. Overall, the proportion of entries in vocational subjects increased, yet there were notable variations in this increase across the areas with different level of deprivation. The rate of the increase in the proportion of entries in Vocational subjects was particularly high in areas with high level of deprivation (e.g. SIMD decile 1) and remained unchanged over the period 2011-2017 in areas with low level of deprivation.

Figure $4 \mathrm{~b}$ is about here

\section{Multilevel regression analysis results.}

So far, we presented the results of the descriptive statistical analysis by considering trends in the reduction of average number of subject entries for National 5 level qualifications, made by student in S4. The findings show an overall reduction in the average number of subject entries with this reduction being particularly large for schools located in areas of higher deprivation. The descriptive results have also shown a trend of changing configurations of subject entries. Yet, it is well known that the level of deprivation of the school postcode area correlates with other characteristics of schools that might be responsible for the number and configuration of subject entries (e.g. Henderson et al 2018). For example, schools in areas of higher deprivation might have fewer subject teachers, offer fewer subjects overall, have lower staff-student ratios and have a higher proportion of pupils from disadvantaged socio-economic backgrounds (ibid). A multivariate regression modelling allows estimation of simultaneous effects of a number of 'independent' (or explanatory) variables that might affect variations in the dependent variable. At the same time, it allows obtaining effects of each independent variable 'net' of controls of other independent variables. In this study, using regression modelling allows better understanding of how a relationship between number of subjects taken by students for National 5 level qualifications and a level of deprivation of school's postcode area is mitigated by characteristics of schools. Similarly, using regression modelling allows better understanding of the relationship between the configurations of subject entries and deprivation across schools of different characteristics. Since schools are 'nested' in local authorities, the number and composition of subject choices are also affected by educational policies and practices existing in that local authority. For this reason, it is important to use multilevel regression that allows modelling the effect of local authorities on the variation of number and compositions of subject entries at schools.

We run 6 regression models for the dependent variable "average number of subject entries per student". The first model is a random intercept model with no independent covariates. Its aim is to estimate the total variance and the variance of the residual (the model's error). This first model then is used as a baseline model, in order to evaluate how much modifying this model and adding independent covariates allows reducing the baseline model's error and to explain the total variance of the dependent variable.

Model 2 has six covariates representing the year when subject entries have been made. An examination of the results of this model shows that there was no gradual reduction in the number of subject entries over the period 2011-2017, but instead there were two drops in the number of entries, one in academic year 20132014, and another one in the following year; subsequently, the average number of subject entries remained rather stable over the period 2015-2017. Therefore, it was decided to create a new variable, 'year grouped', 
with the grouping of the years reflecting the periods of stability and years of changes in number of subject entries and use this new variable as an independent covariate in the subsequent models.

Model 3 has three categories of variable 'year grouped' (1: years 2011-2013, the reference category; 2: 2014; 3: 2015-2016) as independent covariates. Examination of the Model 3 level 2 variance and its residual variance allows assessing how well adding the variables that stand for the period of introduction of new qualifications allows reducing the model's total error compared to the baseline model and explaining the part of the total level 2 (local authorities' level) variance.

Model 4 and Model 5 has further independent covariates. A gradual introduction of the independent covariates allows a) assessing the reduction in the size of the model's error/model's fit improvement as a result of the introduction of new covariates and b) estimating the impact of each independent covariate on the dependent variables net of controls of other independent variables. Model 6 also included interaction terms between independent covariate and the period of introduction of new qualifications and aims to assess whether there were differences in the impact of the independent covariates on the dependent variable before, during and after the introduction on new qualifications under the CfE.

The first column in Table 1 (Model 1 ) is a random intercept model with no covariates. The results show that over the period 2011-2017, the predicted average number of subject entries was 6.2; this varied across local authorities, with a variance 0.16 , and the variance of the residual (the model's error) was 2.32 . Model 2 is a random intercept model with six covariates, representing years of enrolment in National 5 qualifications, with 2011 being the reference category. The model's intercept is allowed to vary between local authorities. The fix part of the model's intercept (value 'Constant' in Model 2, Table 2) 7.3, shows the average number of subject entries for the reference year. The fixed effects of the independent covariates (dummy variable representing the year of subject entries) show how the number of subject entries was different in a corresponding year compared to the reference year. The total variance of number of subject entries for all schools is $1.34^{8}$ and thus, between-local authority variance makes up a proportion 0.142 of this total variance ${ }^{9}$. This proportion is the intra-local authority correlation that measures the extent to which the average number of subject entries in the same local authority resemble each other, as compared to those of schools from different local authorities. This model shows an almost $50 \%$ reduction in error compared with Model 1 , which means that year of subject enrolment explains well the total variance of the dependent variable, both on schools' and local authorities' levels. A comparison between the model's Chi-square and Wald Chi-square suggests that two-level model fits well the empirical data, compared with OLS regression.

A consideration of fixed effect of the covariates shows that the impact of years 2014 and the following years on the number of subject choices is negative. This magnitude of this impact increased after 2014 and remained almost unchanged over the period 2015-2017. A predicted number of subject entries made by students decreased by 1.77 in 2014 and by 2.15 in 2015, compared to the reference year, 2011.

Table 3 is about here

In Model 3, the intercepts and slopes of the covariates 'year grouped' are allowed to vary across level 2 units, local authorities. A covariance between year and the random intercept is also added to the model. This model has an improved fit, compared to Model 2. Its residual variance is also smaller than that of model 2. The intercepts of individual local authorities are different. The average number of subject choices during the period 2011-2013 is 7.35, with this average varying across local authorities, with variance 0.29 . The average reduction in the number of subject choices for year 2014 is 1.8 and the mean reduction in the number of

\footnotetext{
${ }^{8}$ This is the sum of the level 2 (local authorities) variance and the variance of the residual, $0.19+1.25=1.34$;

${ }^{9}$ Intra-local authority correlation = variance $($ Local Authorities $) /$ Total school variance=0.19/1.34=0.142
} 
subject choices for the period 2015-2017 is 2.1, compared to the reference period 2011-2013. However, the individual local authority slopes vary around these average values, with variance 0.12 . In addition, there is also a negative covariance between intercepts and slopes estimated as -0.11 (and this corresponds to a correlation $0.59^{10}$ between the intercepts and slopes across local authorities), suggesting that local authorities with a higher number of subject entries in years 2011-2013 tend to have less steep slopes, which means that they have experienced more moderate decline in the number of subject entries than local authorities with lower number of subject entries in years 2011-2013. Intra-local authority correlation (a degree to which schools within the same local authority resemble each other) estimated by this model is 0.20 .

Model 4 includes further independent covariates, a school postcode area's deprivation decile, with decile 1 (the highest level of deprivation) as a reference category. The intercepts and slopes of these independent covariates are allowed to vary across the local authorities. Covariances between (a) year and the random intercept and (b) deprivation decile and random intercept are also added to the model. The fit of this model improved further, with a $13 \%$ decrease in the variance of the residual, in comparison with model 3 . The average number of subject choices for schools in the most deprived areas during the period 2011-2013 is 6.79, with the average varying across local authorities with variance 0.73 . In most deprived areas the average reduction in the number of subject choices for year 2014 is 1.78 and an average reduction in the number of subject choices for the period 2015-2017 is 2.12, compared to the reference period 2011-2013. However, the reduction was smaller in less deprived areas; fixed parts of the estimated parameters of all deprivation deciles are positive, and an increase in magnitude of the values of estimated parameters corresponds to a decrease in the level of deprivation of school's postcode area (see column in Table 3).

The individual local authority slopes vary around each years' average values, with variance 0.12 . The individual local authority slopes vary around area deprivation levels' average values with variance 0.01 . In addition, there is also a negative covariance between intercepts and slopes for years and area level of deprivation. The value of covariance between random intercepts and slopes of variable 'year grouped' is $-0.16^{11}$ and the value of covariance between random intercepts and slopes of variable 'deprivation decile' is $-0.06^{12}$, suggesting not only that local authorities with higher number of subject choices in years 2011-2013 have experienced more moderate decline in the number of subject choices over the years, but that local authorities with higher than average number of subject choices in the most deprived areas have less variation in the number of subject choices by deprivation deciles. An absence of correlation between variances of 'year grouped' and 'deprivation decile' variables show that this was true for the entire period. The intra-local authority correlation estimated by this model is 0.42 , which means that controlling for school postcode area's level of deprivation increases a degree of similarities of schools within the same local authority (or, in other words, within a local authority schools within the same deprivation decile are more alike, than schools across different deprivation deciles).

Finally, Model 5 includes further independent covariates, school characteristics, as well as random intercepts and random slopes for covariates 'year grouped' and 'SIMD decile' that vary across local authorities. The covariances between (a) year-grouped and the random intercept and (b) deprivation decile and random intercept are also added to the model. The fit of this model improved further, with a $10 \%$ decrease in the variance of the residual in comparison with Model 4 . The average number of subject entries for the reference period 2011-2013 is 9, with the average varying across local authorities with variance 0.74 . The average reductions in the number of subject entries in 2013 and 2014 (fixed parts) are similar to those predicted by Model 4. The magnitudes of the fixed parts of the estimated parameter for all deciles of deprivation are

\footnotetext{
${ }^{10}$ Corr (year, intercept $)=\operatorname{cov}($ year, intercept $) / \operatorname{vvar}($ intercept $) * \operatorname{var}($ year $)=-0.11 / v 0.12 * 0.29=-0.59$

${ }^{11}$ The value of correlation between the random intercepts and slope of variable 'year grouped' is -0.48

12 The value of correlation between random intercepts and slopes of variable 'deprivation decile' is -0.60 .
} 
smaller than those estimated by Model 4, indicating that there might be a correlation between characteristics of schools and a school postcode area's level of deprivation.

Compared to schools in large urban areas, schools in rural areas (both accessible and remote), as well as schools in remote towns, have on average a larger number of subject entries made by a student. The overall number of subjects in school, which can be taken for SCQF National 5 qualifications, is positively associated with the number of subject entries. A higher staff/student ratio ${ }^{13}$ is positively linked to the number of subject entries ${ }^{14}$. The number of students on free meals and the proportion of students with additional learning support needs are negatively linked to the number of subject choices at school. The proportion of pupils from black or ethnic minority background at school was not found to be linked to the average number of subject entries per student.

The individual local authority slopes vary around average value of categories of the variable 'year grouped', with variance 0.13 , and around average values of variable 'school postcode area's deprivation decile', with variance 0.01 . In addition, there is also a negative covariance between intercepts and slopes for variables 'year grouped' and 'school postcode area's level of deprivation'. The value of covariance between random intercepts and slopes of the variable 'year grouped' is -0.16 and the value of covariance between random intercepts and slopes of variable 'deprivation decile' is -0.05 , similar to those estimated by Model 4 . The correlations were -0.51 between the intercept and slope of the 'year grouped' variable across local authorities, and -0.63 between the intercept and slope of 'deprivation decile' variable. Intra-local authority correlation estimated by this model is 0.44 .

Overall the reduction in the residual variance between model 5 and model 1 is $59 \%$. Yet, the variable 'year grouped' that that stands for the period of introduction or new qualifications under the CfE, accounts for $49 \%$ of the total variance, the school postcode area's level of deprivation accounts for further $7 \%$ percent of the total variance and, only $3 \%$ of the total variance of the residual is accounted for by school characteristics.

In Appendix 2 we provide additional information about the way estimates of Model 5 fit the empirical data. (see Figures A2.a-A2.f). Thus, Figure A2.a plots predicted values of number of subject entries against the observed values and shows a strong linear relationship between the two, while Figure A2.b plots fixed part vs random part of the predicted values of nimber of subject choices. Figures A2.c-A2.f allows visualisation of the final model fit. They plot (a) observed and (b) predicted values of subject choices by year and area deprivation decile, and shows that estimated values fit well the empirical data.

\section{Over-time changes in the relationship between subject choice and school characteristics.}

To assess the over-time changes in the relationship between the school characteristics and the number of subject entries, we have run one more regression model that is specified similarly to Model 5 , but additionally includes interactions between variable 'year grouped', which stand for the period of introduction of new qualifications, and independent variables, such as a school's area deprivation decile, type of residential locality, staff-student ratio, number of students on free meals, percentage of students with additional learning support needs, and number of subjects available at schools for National 5 level qualifications (see Table 3.1).

\footnotetext{
${ }^{13}$ We carried out additional sensitivity analysis (see Appendix 3 ) by running a regression model similar to Model 5 where we controlled for the size of S4 roll instead of staff-student ratio (see Table 3A.1). The results show regression coefficients estimated by this model are very similar to the regression coefficients estimated by Model 5 .

${ }^{14}$ Both variables, size of school (number of students) and the number of full-time teachers, are positively related to the number of subject entries. Many secondary schools are very large, therefor a staff/student ratio variable, if defined as a number of teachers divided by number of students, acts as an inverse value for the school size and has a negative effect on the dependent variable. In order to reduce the effect of very large schools, we defined staff-student ratio as number of full-time teachers in school divided by natural logarithm of number of students in school.
} 
Column 1 in Table 3.1 presents the main effects. The main effects refer to the regression coefficients of the independent variables during the baseline/reference period (i.e. 2011-2013, the period prior to introduction of new qualifications). Column 2 presents the regression coefficients of interactions between the corresponding independent variables and the year 2014. Thus, figures presented in this column show the increments (either negative or positive) to the main effects. In other words, they show how much the effect of the independent variables changed (increased, decreased or remained the same) in the corresponding year/period compared to the reference period. Similarly, column 3 presents the regression coefficients of interactions between the corresponding independent variables and the period 2015-2017.

Over-time change in the impact of the level of area deprivation on the number of subject choices. The main effects of the variable 'deprivation deciles' are small in magnitude, demonstrating that, prior to the introduction of new qualifications under $\mathrm{CfE}$, there was a little variation in the number of subject entries at the SCQF level 5, across schools in areas with different level of deprivation. Regression coefficients of the interaction terms between year 2014 (the year the new qualification were in force) and the deprivation deciles are presented in column 2 of Table 3.1, and show that the largest reduction in the predicted number of subject entries, net of the effect of other independent covariates, was in the decile of the highest deprivation (decile 1), while the smallest reduction in the number of subject entries was in areas with the least level of deprivation (decile 10). The regression coefficients of interactions between the period 2015-2017 and the school area deprivation decile (column 3 in Table 3.1) are negative and there is a little variation in the size of the coefficients across deprivation deciles. Figure 5 presents variations in the net impact of deprivation decile on the numbers of subject entries (adopted from Table 3.1).

Over-time change in the impact of the number of students on free school meals on the number of subject choices. The impact of the number of students on free school meals on subject entries was negative during the reference Perion, 2011-2013 (the regression coefficient of the interaction term is -0.003). This negative impact increased over time and become stronger in 2014 (the regression coefficient of the interaction term 0.002), and this negative effect strengthened further during 2015-2017 (the regression coefficient of the interaction term -0.003).

Over-time change in the impact of the level of area deprivation on the number of subject choices. The figures presented in Table 3.1 show that the interaction terms between the type of locality and the period of introduction of new qualifications were small in magnitude. All types of localities experienced a moderate reduction, compared with the reference category.

Over-time change in the impact of the staff-student on the number of subject choices. Impact of the staffstudent ratio on the subject entries was positive in 2011-2013; it became stronger in 2014 and went back to the level similar to that of the reference period during 2015-2017.

The impact of the percentage of students with additional support needs on the number of subject entries was small over 2011-2013, then the impact become negative and its magnitude increased in 2014 and then again during 2015-2017.

\section{Modelling the subject entries.}

In Tables 4 and 5, we present the result of multilevel modelling of the percentage of subject entries into each one of seven subject groups (see Appendix 1). The level of observation is secondary schools in Scotland (level 1), nested in Scotland's local authorities (level 2). Each regression model includes local authority level random intercepts and random slopes and the following fixed characteristics: the period of the CfE introduction, the school's postcode (local area) level of deprivation, the region in Scotland, and school characteristics such as student/teacher ratio, number of students on free means [sic] and percentage of students with special learning support needs. The intercepts and the slopes of covariates 'year grouped' (i.e. the period of the CfE introduction) and 'SIMD decile' (schools' area level of deprivation) are allowed to vary across local authorities. The models also include covariances between (a) year and the random intercept and (b) deprivation decile and random intercept. 
Table 4 is about here

\section{English}

The fixed part of the model's intercept shows that on average predicted proportion of English entries accounted for 13 percent (value 'Constant ${ }^{\prime 15}$ in Model 1 is 13) of all subject entries during the reference period (2011-2013). This average varied across local authorities with variance 4.24. On average, deprivation deciles had a small negative effect on the proportion of English entries compared with the reference category, deprivation decile 1. Yet, these average effects varied across local authorities with variance 0.05 . The fixed effects of the independent covariates for the period of the CFE introduction show that the percentage of English entries slightly increased in 2014 and then increased again during 2015-2017. Again, there was a variation in these average effects across local authorities (variance 0.38 ). The total variance of the dependent variable for all schools is $13.19^{16}$ and thus between-local authority variance makes up a proportion 0.32 of this total variance ${ }^{17}$. This proportion is the intra-local authority correlation that measures the extent to which the percentage of entries in English in schools within the same local authority resemble each other, as compared to those of schools from different local authorities. A comparison between the model's Chi-square and Wald chi-square shows that this two-level model fits well the empirical data, compared with OLS regression.

There was a strong negative correlation $(-0.74)$ between the period of introduction of new qualifications (yeargrouped) and intercept for English entries, indicating that the change in the proportion of entries in this subject was considerably slower for local authorities that used to have higher proportion of entries in this subject during 2011-2013. There was also a strong negative correlation $(-0.76)$ between deprivation decile and intercept ${ }^{18}$, indicating that the proportion of entries in English was less differentiated by deprivation deciles in local authorities with a higher proportion of entries in this subject in deprivation decile 1 (the most deprived decile).

English entries were not differentiated by the type of locality. Staff/student ratio did not affect the proportion of English entries. A higher proportion of students on free meals was linked to a higher proportion of English entries. Given that English is a compulsory subject for National 5 qualifications, this means that students in such schools were less likely to enrol in a variety of subjects.

\section{Maths}

The average predicted proportion of Maths entries accounted for 16.2 percent (see value 'constant in the 'fixed' part of Model 2, Table 4) of all subject entries during the reference period (2011-2013). This average varied across local authorities with variance 2.22. The fixed effects of the independent covariates for the period of the CfE introduction show that this percentage slightly decreased in 2014 and then increased again during 2015-2017. There was a variation in the average effect of 'year-grouped' across local authorities (variance 0.26), indicating that the trends were different for different local authorities. Although on average Maths entries were not differentiated by deprivation deciles, there was small variation in these effects across local authorities (variance 0.04). The total variance of the dependent variable for all schools was $10.72^{19}$ and thus, the intra-local authority correlation was $0.21^{20}$. A comparison between the model's Chi-square and Wald chi-square shows that this two-level model fits well the empirical data compared with OLS regression. The correlation between slopes and intercepts of variable 'year-grouped' for Maths entries was negative (-0.5),

\footnotetext{
15 'Constant' notation stands for the fixed part of the intercept

${ }^{16}$ This is the sum of the level 2 (local authorities) variance and the variance of the residual, 4.24+8.95=13.19.

17 Intra-local authority correlation = variance (Local Authorities)/Total school variance, 4.24/13.19=0.32.

${ }^{18} \operatorname{Corr}($ SIMDdecile, intercept $)=\operatorname{cov}($ SIMDdecile, intercept $) / \operatorname{vvar}($ intercept $) * \operatorname{var}($ SIMDdecile $)=-0.76$

${ }^{19}$ This is the sum of the level 2 (local authorities) variance and the variance of the residual, $2.22+8.7=10.72$.

${ }^{20}$ Intra-local authority correlation = variance (Local Authorities) $/$ Total school variance, 2.22/10.72=0.21.
} 
indicating that the proportion of math entries decreased less over years in local authorities where this proportion used to be higher during 2011-2013. There was also a strong negative correlation (-0.83) between deprivation decile and intercept, indicating that the proportion of Maths entries was less differentiated by deprivation deciles in local authorities, which had a higher proportion of Maths entries in the highest deprivation decile.

Similarly to English entries, Maths entries were not differentiated by the type of residential locality (by its size and urban/rural indicator). Staff/student ratio did not affect the proportion of Maths entries. Yet, higher proportion of students on free meals was linked to lower proportion of entries in Maths subjects.

\section{Science Subjects}

On average, the predicted proportion of entries in Science subjects accounted for 17.3 percent of all subject entries during the reference period (see value of 'constant' in the 'fixed' part of Model 3, Table 4). This average varied across local authorities with variance 8.03. There was an average increase in the percentage of Science subject entries both in 2014 and then during 2015-2017, compared to the reference period (2011-2013) (see fixed effects of the independent covariates for the period of the CfE introduction, year-grouped). There was a variation in the percentage of Science Subjects' entries across areas with different level of deprivation, with the decile 10 (least level of deprivation) having the strongest positive impact on the proportion of Science subjects' entries. The average effects of 'year grouped' and 'deprivation deciles' variables vary across local authorities. It is worth noting that the variance of the average effects of 'deprivation deciles' across local authorities is 0.16 , four-fold higher than the correspondent variations in English and Maths entries, suggesting that local authorities differ in relation to Science Subject entries considerably more than in relation to Maths and English entries. The total variance of the dependent variable is $23^{21}$ (again much higher than the total variance of the dependent variables 'Maths entries' and 'English entries') and the intra-local authority correlation is $0.39^{22}$, meaning that, in terms of Science subjects' entries, schools within the same local authorities resemble each other more strongly, than in terms of English and Maths entries.

The correlation between year-grouped variable and intercept for Science subjects entries was small in magnitude. However, we found a strong negative correlation $(-0.65)$ between variable 'deprivation decile' and intercept, indicating that the proportion of Science subjects' entries was less differentiated by deprivation deciles in local authorities with higher proportion of Science subjects entries in the highest deprivation decile.

The consideration of the fixed effects of other covariates shows that percentage of Science entries was differentiated by the deprivation decile. Almost in every decile proportion of entries in Science subjects was higher than in decile 1 (the most deprived decile), however the highest proportion of entries in Science subjects was in areas of the least deprivation (decile 10). The proportion of Science subjects entries was positively affected by staff/student ratio, while the negative effect of the number of students on free school meals on the percentage of entries was stronger for Science subjects than for Maths.

Table 5 is about here

\section{Modern Languages}

On average, the predicted proportion of entries in Modern Languages was 9.5\% (see value of 'Constant' in the 'fixed part' of the model in column 2, Table A5) during the reference period of 2011-2013. This average varied across local authorities with variance 7.92. The proportion of entries in Modern Languages decreased

\footnotetext{
${ }^{21}$ This is the sum of the level 2 (local authorities) variance and the variance of the residual, 8.06+13.09=21.15.

22 Intra-local authority correlation = variance (Local Authorities) $/$ Total school variance, 8.06/21.15=0.38.
} 
dramatically, first in 2014 and then again during 2015-2017. There was a variation in the effect of the 'year grouped' variable across local authorities (variance 0.5). Although on average, Modern Languages entries were not differentiated by deprivation decile, there were variations in the impact of deprivation decile on the proportion of entries in Modern Languages across local (see values of var(SIMDdecile) in Table 5). The number of students on free meals was found to be negatively related to the proportion of Modern Languages entries. Schools that have higher staff/student ratios were found to have higher proportion of Modern Languages entries. The total variance of the dependent variable was $15.2^{23}$ (much higher than the total variance of the dependent variables 'Maths entries' and 'English entries') and the intra-local authority correlation was $0.51^{24}$, meaning that, in terms of Modern Languages entries, schools within the same local authorities resemble each other more strongly, than in terms of English, Maths and Science Subjects entries.

The correlation between year-grouped and the intercept for Modern Languages entries was low, indicating that, on average, local authorities experienced a similar over-time decline in the proportion of Modern Languages entries. However, we found a strong negative correlation $(-0.85)$ between deprivation decile and intercept, indicating that the proportion of Modern Languages entries was more differentiated by deprivation deciles in local authorities where there was a lower than average proportion of Modern Languages entries in the most deprived decile.

\section{Vocational subjects}

The predicted proportion of vocational subject entries during 2011-2013 was $21.7 \%$ (see value of 'Constant' in the 'fixed part' of the model in column 3, Table 5). This average varied across local authorities with variance 13.6. On average, the size of this proportion changes only a little over 2014-2017. Yet, there was a variation between different local authorities in the effect of the 'year-grouped' variable with variance 0.55 . The proportion of vocational subjects' entries is strongly differentiated by the school postcode area's level of deprivation, with schools in the most deprived areas having a higher proportion of such entries, while schools in the least deprived areas have the lowest proportion of entries in vocational subjects (see column 4 in Table 5). The number of students on free school meals and the proportion of students with additional learning support needs in school were both linked positively to the proportion of vocational subjects entries. Teacher/student ratio was negatively linked to the proportions of vocational subject entries, indicating that more pupils entered vocational subjects in schools where fewer full-time teachers are available per student.

There is also a negative covariance between intercepts and slopes of deprivation deciles variable (with correlation -0.84), suggesting that local authorities with a higher than average proportion of vocational subject entries in the most deprived areas have less variation in proportion of subject entries across areas with different levels of deprivation. Intra-local authority correlation estimated by this model is 0.36 .

\section{Conclusions}

A secondary education system has always had a duty to better, to educate, to broaden horizons, and to equip young people on the threshold of the adulthood with a wide range of contemporary knowledge. This task was emphasised much earlier than the task to produce measurable educational outcomes (such as secondary qualification exams grades), which have become predominant in modern societies, and modern secondary education should certainly not be reduced to function just as a grade factory, releasing highly achieving but otherwise broadly ignorant individuals into adult life. As the previous example of a matriculation certificate obtained in the late $19^{\text {th }}$ century shows, historically secondary education has had a remit to equip young

\footnotetext{
${ }^{23}$ This is the sum of the level 2 (local authorities) variance and the variance of the residual, $7.92+7.36=15.24$

${ }^{24}$ Intra-local authority correlation = variance (Local Authorities) $/$ Total school variance, 7.92/15.24=0.51.
} 
people with a broad spectrum of knowledge that ranged from maths, geology, physics and physiology, to history, botany and geography, and to arts, music and physical education. Equipping young people with a broad range of knowledge is particularly important in contemporary society, as the internet provides an exponentially increasing access to unverified information on everything. A systematic and in-depth study of disciplinary knowledge in history, geography, natural sciences, etc., offers young people an opportunity to be able to critically access and verify information that they consume through various media sources. Teaching such skills, as well as developing intellectual curiosity and flexibility, open-mindedness, cultural sensitivity, achieved through learning foreign languages, arts, philosophy, etc., should be considered as important as equipping young people with good grades. Nor should the claims about the inverse relationship between the number of subjects studied and attainment be made prior to the rigorous study of the nature of such relationship. Furthermore, a relationship between a reduced number of subjects studied for National Qualifications at age 16 and a wide range of outcomes other than exam attainment should be studied.

The aim of this study was to explore the ways in which CfE affected the senior phase of Scottish secondary education system. In particular, we aimed to find out whether the secondary senior phase has narrowed over the period of the introduction of the $\mathrm{CfE}$, and identify the characteristics of schools that might be responsible for the variations in curriculum narrowing.

Our findings confirmed that there was indeed a wide-spread reduction in subject enrolment and in the number of subject choices of 14-15-year-old pupils over the period of 2011-2017. The main reduction in the number of subject entries and the number of subject choices took place during 2013-2014, when new National 3-5 level qualifications were introduced. Yet, the size of this reduction was not uniform, but varied between schools of different characteristics, between areas with different level of deprivation and between local authorities in Scotland.

Our findings confirmed our first research hypothesis that the introduction of the senior phase of the CfE has increased a variation across secondary schools in Scotland in subject enrolment and in the configuration of subject entries. Our second set of hypotheses has also been confirmed. We found that the secondary school senior phase curriculum has become more differentiated by characteristics of schools, than prior to the introduction of new qualifications under the CfE. Thus, schools' characteristics do matter; a school's composition - in terms of number of children on free meals, number of children with additional learning support needs, teacher student ratio and overall number of subjects available in school - provides significant predictors of the number of subject choices. Furthermore, the level of deprivation of a school's postcode area (measured by the SIMD decile) has an additional effect on the number and the configuration of subject choices, after accounting for the above school level characteristics.

We also found that local authorities are important in shaping the secondary school curriculum - our findings show that there is a large degree of a similarity between schools within the same Local authority, as well as substantial variations between different local authorities in terms of the number and configuration of subject choices. Furthermore, we found that local authorities that on average used to have higher number of subject entries student, prior to the introduction of new qualifications under the CfE, were less affected by the new curriculum - they have experienced a smaller reduction in the number of subject choices. Similarly, in these local authorities the number of subject choices were less differentiated by the level of deprivation of a school's postcode area.

In an accordance with existing literature (e.g. Henderson et al. 2018) we found that subject choice could be affected by availability of subject teachers. Thus we found that in schools with higher staff/student ratio, students are more likely to select more subjects as well as to select such subjects as Sciences, Social Sciences and Modern Languages. We also found that the overall range of subjects offered in S4 for National 5 level qualifications has a net positive effect on the number of subject choice - in schools that offer more subjects, students enter more subjects for National 5 qualifications. Together these findings suggest that staffing issues are important for subject choice and lack of subject teachers might be responsible for the curriculum narrowing. 
We did not find a systematic evidence that the number of subject entries, as well as their configuration, is differentiated by the ethnic composition of school. However, we did find that the size of residential locality and rurality have impact on the average number of subject entries, with the number of subject entries per student being higher in small towns and in rural localities. This evidence of regional variations in number of subject entries indicates that there might be regional differences in curriculum policies, and suggests a need for further (including qualitative) research in schools located in different local authorities, and in different regions in Scotland.

Most importantly, we found that characteristics of schools, such as the level of deprivation of a school's postcode area and the socio-economic and ability compositions of a school's intake have a strong association with subject choice. Thus, a larger reduction in the number of subject entries for National 5 level qualifications took place in schools in more deprived areas, as well as in schools with a larger number of students from disadvantaged socio-economic background, and schools where the proportion of pupils with additional learning support needs was higher.

Similarly, the findings show that the SES composition and the ability compositions of schools' intakes have a strong association with configurations of subject choices. Thus, schools in areas of higher deprivation and schools with larger numbers of pupils from disadvantaged backgrounds have smaller proportions of young people enrolled in Sciences and Modern Languages, and a larger proportion of pupils enrolled in vocational subjects.

Furthermore, we found that the impact of school characteristics on the number of subject entries increased over time. Thus, we found that a negative effect of the number of students on free school meals on the number of subject entries made by 15 -year-old pupils increased over the period of the introduction of new qualifications under CfE , with this effect becoming twice as strong during 2015-2015 than prior to 2014.

We also found that not all subjects were affected by the phenomena of the curriculum narrowing in a similar way. Thus, the proportion of entries into such core subjects as English and Maths either increased (English) or remained relatively stable over the time (Maths). The increase in the proportion of English entries is positively associated with a larger number of students from disadvantaged social backgrounds in school. Since English always was and is a compulsory qualification in S4, with (as a rule) one entry for every student, a proportionate increase does not mean that more students are taking English, but that they take fewer other subjects. Neither the proportion of entries in English nor the proportion of entries in Maths were affected by the school area's level of deprivation. The proportion of both Modern Languages and Arts entries decreased, and while these decreases were not differentiated by the schools' local area level of deprivation, the proportion of entries in Modern Languages was found to be linked with the socio-economic composition of a school's intake and was negatively affected by the number of students on free schools meals.

The findings show that, for all subjects but Modern Languages, the reduction in the proportion of subject entries was not continuous but occurred over two years, 2013-2014 and 2014-2015. Yet, the reduction in the proportion of the Modern Languages entries started before the introduction of the new qualifications and continued at least until 2017. Therefore while we can assume that the introduction of new qualifications could be reasonably held responsible for the changes in the configuration of subject choice, the phenomena of the reduction in entries in Modern Languages goes beyond the influences of the $\mathrm{CfE}$, and is a part of a longer, perhaps UK-wide trend.

Our findings show that schools with higher number of pupils from disadvantaged backgrounds have a lower proportion of entries in such facilitation subjects such as Modern Languages and Sciences and higher proportion of entries in vocational subjects, thus indicating that the phenomenon of curriculum narrowing and the reduction in subject choices disproportionally affect students from disadvantaged socio-economic backgrounds. Existing research evidence shows that in the Scottish education system subject choices made by young people in $\mathrm{S} 4$ are strongly related to subject choices made later, in S5 and S6, and to career opportunities of young people and their ability to make a transition to Higher Education (Iannelli, Smyth \& Klein 2016). 
Therefore, the narrowing of the curriculum and the reduction of choice might have an adverse effect on socialeconomic mobility opportunities for young people from disadvantaged socio-economic background.

Existing research evidence shows a clear link between subject choices of young people at senior stages of secondary education and their family background, gender and prior attainment (ibid). Our findings confirm existing research evidence that school characteristics are also important for individual subject choices (Anders et al 2018). Yet, the mechanism that links between school characteristics and individual subject choice is not entirely clear and more research is needed to understand how schools influence the subject choices of young people. It is especially important now, since CfE has increased the autonomy of schools in curriculum provision, and hence increased the role that schools might play in subject choices of young people.

In order to gain better insights into how patterns of curriculum provision relate to visible phenomena such as curriculum narrowing and their subsequent impact on educational opportunities for young people from different socio-economic backgrounds, it is necessary to generate missing data, including qualitative datasets, about patterns of provision, the role of schools and teachers in shaping provision and curriculum decisionmaking. These new data need to be analysed in conjunction with the analysis of secondary data sources on subject choices, attainment and early destinations of young people in Scotland, with findings from such research informing current and future curriculum policies and practices. 


\section{References}

Altonji, J. G., Blom, E., \& Meghir, C. (2012). Heterogeneity in human capital investments: High school curriculum, college major, and careers. Annual. Review of Economics, 4(1), 185-223.

Anders, J., Henderson, M., Moulton, V., \& Sullivan, A. (2018). The role of schools in explaining individuals' subject choices at age 14. Oxford Review of Education, 44, 75-93.

BBC (2014). A guide to the new National 4 and 5 qualifications. https://www.bbc.co.uk/news/uk-scotland$\underline{27032316}$

Chevalier, A. (2011). Subject choice and earnings of UK graduates. Economics of Education Review, 30, 11871201.

Chmielewski, A. K. (2017). Social Inequality in Educational Transitions under Different Types of Secondary School Curricular Differentiation. Ch. 1.2. (pp. 51-72) in Pathways to Adulthood: Educational Opportunities, Motivation and Attainment in Times of Social Change, edited by Ingrid School and Rainer Silbereisen. London: UCL IoE Press

Coleman, J. S., Campbell, E. Q., McPartland, J., Mood, A. M., Weinfeld, F. D., \& York, R. L. (1966). Equality of Educational Opportunity. National Center for Educational Statistics, U.S. Department of Health, Education, and Welfare, Washington, DC.

Davies, P., Adnett, N. \& Turnbull, A. (2003). Market forces and diversity: some evidence from the 14-19 curriculum. Journal of Curriculum Studies, 35, 4, 479-498.

Davies, P., Telhaj, S., N. Adnett, Coe, R. \& Hutton, D. (2009a). Competition, cream-skimming and department performance within secondary schools. British Educational Research Journal, 35, 65-81.

Dilnot, C. (2018). The relationship between A-level subject choice and league table score of university attended: the 'facilitating', the 'less suitable', and the counter-intuitive. Oxford Review of Education. https://doi.org/10.1080/03054985.2018.1409976

Dolton, P. J. \& A. Vignoles. (2002). Is a Broader Curriculum Better? Economics of Education Review. 21, 415429.

Encyclopaedia Britannica. https://www.britannica.com/biography/Martiros-Saryan

Henderson, M., Sullivan, A., Anders, J., \& Moulton, V. (2018). Social Class, Gender and Ethnic Differences in Subjects Taken at Age 14. The Curriculum Journal, 29, 298-318.

Keddie, A., Mills, M. \& Pendergast, D. (2011). Fabricating an identity in neo-liberal times: performing schooling as 'number one'. Oxford Review of Education, 37, 75-92.

lannelli, C. \& Duta, A. (2018). Inequalities in school leavers' labour market outcomes: Do school subject choices matter? Oxford Review of Education. 44, 56-74.

lannelli, C. \& Smyth, E. (2017). Curriculum choices and school-to-work transitions among upper-secondary school-leavers in Scotland and Ireland. Journal of Education and Work. 30, 731-740.

Iannelli, C. (2013). The role of the school curriculum in social mobility. British Journal of Sociology of Education, 34, 907-928.

lannelli, C., Smyth, E., \& Klein, M. (2016). Curriculum differentiation and social inequality in higher education entry in Scotland and Ireland. British Educational Research Journal, 42, 561-581.

Joensen, J. S., \& Nielsen, H. S. (2009). Is there a causal effect of high school math on labor market outcomes? Journal of Human Resources, 44, 171-198.

Lupton, R. (2005). Social justice and school improvement: improving the quality of schooling in the poorest neighbourhoods. British Educational Research Journal, 31, 589-604.

Lupton, R. \& Thrupp, M. (2012). Headteachers readings of and responses to disadvantaged contexts: evidence from English primary schools. British Educational Research Journal, 39, 1-20.

Marks, G. N. (2015). Are school-ses effects statistical artefacts? evidence from longitudinal population data. Oxford Review of Education, 41, 122-144.

Ofsted (2013). The report of Her Majesty's Chief Inspector of Education, Children's Services and Skills 2013/14: Schools. Annual Report. Ofsted.

Priestley, M. (2014). Curriculum regulation in Scotland: a wolf in sheep's clothing is still a wolf. European Journal of Curriculum Studies, 1, 61-68. 
Raffe, D. \& Howieson, C. (1999). The 'Unification' of Post-16 Education. CES briefing, vol. No 15. Edinburgh: Centre for Educational Sociology.

Rasbash, J. et al., (2002). A User Guide to MLwiN. Version 2.1. Centre for Multilevel Modelling, Institute of education, University of London.

Reform Scotland (2019). National 4 and 5s: The accidental attainment gap.

https://reformscotland.com/2019/04/scottish-state-schools-cut-number-of-exams-pupils-areallowed-to-sit/

StataCorp (2015). Stata Statistical Software: Release 14. College Station, TX: StataCorp LP.

Smyth, E., \& Hannan, C. (2006). School effects and subject choice: The uptake of scientific subjects in Ireland. School Effectiveness and School Improvement, 17(3), 303-327.

Smith, D. J., Tomlinson, S., Bonnerjea, L., Hogarth, T., \& Tomes, H. (1989). The School Effect: A Study of MultiRacial Comprehensives. London: Policy Studies Institute.

Sullivan, A. (2009). Academic self-concept, gender and single-sex schooling. British Educational Research Journal, 35, 259-288.

Shapira, M. \& Priestley (2018) Narrowing the Curriculum? Contemporary trends in provision and attainment in the Scottish Curriculum. Scottish Educational Review, 50, 75-107.

The Guardian (2017). Proportion of students taking arts subjects falls to lowest level in decade. https://www.theguardian.com/education/2017/sep/21/proportion-of-students-taking-arts-subjectsfalls-to-lowest-level-in-decade

The Guardian (2018). A-level results: foreign languages suffer further slump. https://www.theguardian.com/education/2018/aug/16/a-level-results-foreign-languages-sufferfurther-slump

The Herald (2019). Narrowing of curriculum 'putting education of generation of pupils at risk'. https://www.heraldscotland.com/news/17595290.narrowing-of-curriculum-putting-education-ofgeneration-of-pupils-at-risk/

The Scotsman (2019). Nicola Sturgeon accused of 'ignoring' teachers on subject choice. https://www.scotsman.com/news/politics/nicola-sturgeon-accused-of-ignoring-teachers-on-subjectchoice-1-4915181

The Telegraph (2017). Dramatic decline in number of university students taking modern foreign languages. https://www.telegraph.co.uk/education/universityeducation/11412441/Dramatic-decline-innumber-of-university-students-taking-modern-foreign-languages.html

Times Educational Supplement (2018). Is Scotland's curriculum really narrowing? https://www.tes.com/news/scotlands-curriculum-really-narrowing

Willms, J. D. (1986). Social class segregation and its relationship to pupils' examination results in Scotland. American Sociological Review, 51, 224-241.

Woods, P. (1976). The myth of subject choice. British Journal of Sociology, 27, 130-149. 
Tables 
Table 1. Variables in the study.

Independent variables

School characteristics

Size of school

Total number of students in a school

Number of qualified teachers

Teacher/Student ratio

Size of S4 roll

Number of qualified teachers divided by total number of students

Number of students on free meals

Percentage of students from black and ethnic minority background

Number of students in year 4

$5 \%$ or less

between $5-10 \%$

between $10-15 \%$

between $15-20 \%$

$20 \%$ or more

Percentage of students with additional

Number of students with special needs divided by total number of students 100

support needs

SCQF level 5 qualifications

Intermediate 2 at A-C; National 5 at A-C; Standard Grade (Credit)

Total number of entries to SCQF level 5

qualifications in $\mathbf{S 4}$ in school

Total number of subjects at National 5

level of qualifications, available in S4

Subject groups (see table A1 in Appendix

1)

English

Maths

Sciences

Social Sciences

Arts

Modern languages

Vocational subjects

Number of entries per subject groups

Total number of entries in each of the subject groups (for National 5 level qualifications in S4).

Rural/Urban Area indicator

Large urban area

Other urban areas

Assessable small towns

Other small towns

Assessable rural area

Remote rural area

Deprivation level school's postcode area

Scottish Index of Multiple deprivation

Level 1 - highest level of deprivation

Level 10 - lowest level of deprivation

\begin{tabular}{|l|l|}
\hline Year & $2011 \ldots 2017$ \\
\hline Year grouped & $2011-2013$ \\
& 2014 \\
& $2015-2017$ \\
\hline
\end{tabular}

Dependent variables

Number of subject entries per student

Total number of entries to SCQF level 5 qualifications in S4 divided by total number of students in S4

Percentage of entries per subject groups

Total number of entries in each of the subject groups, divided by total number of entries to SCQF level 5 qualifications in S4 in school, multiplied by 100 


\begin{tabular}{|c|c|c|c|c|c|c|c|c|c|}
\hline year & & $\begin{array}{c}\text { Total } \\
\text { number } \\
\text { of } \\
\text { entries }\end{array}$ & $\begin{array}{l}\text { Number } \\
\text { of } \\
\text { entries } \\
\text { per } \\
\text { students }\end{array}$ & $\begin{array}{c}\text { Teacher } \\
\text { s/ } \\
\text { student } \\
\text { ratio }\end{array}$ & $\begin{array}{c}\text { Stage } 4 \\
\text { roll }\end{array}$ & $\begin{array}{l}\text { Students } \\
\text { register } \\
\text { ed for } \\
\text { free } \\
\text { school } \\
\text { meals }\end{array}$ & $\begin{array}{c}\text { School } \\
\text { Roll }\end{array}$ & $\begin{array}{l}\text { Number } \\
\text { of } \\
\text { qualified } \\
\text { teachers }\end{array}$ & $\begin{array}{c}\text { Average } \\
\text { number } \\
\text { of } \\
\text { subjects } \\
\text { in schoo }\end{array}$ \\
\hline \multirow[t]{2}{*}{2011} & Mean & 1138 & 7.26 & 0.09 & 156.16 & 116.43 & 838.13 & 68.95 & 20.12 \\
\hline & Std. Dev. & 546.1 & 1.30 & 0.02 & 68.23 & 88.12 & 358.28 & 25.14 & 2.57 \\
\hline \multirow[t]{2}{*}{2012} & Mean & 1127 & 7.33 & 0.09 & 153.44 & 113.50 & 828.71 & 66.99 & 19.96 \\
\hline & Std. Dev. & 554.3 & 1.37 & 0.02 & 67.85 & 81.05 & 355.57 & 24.54 & 2.93 \\
\hline \multirow[t]{2}{*}{2013} & Mean & 1139 & 7.34 & 0.09 & 152.91 & 117.92 & 823.12 & 67.01 & 20.02 \\
\hline & Std. Dev. & 559.9 & 1.36 & 0.02 & 68.26 & 84.67 & 355.61 & 24.53 & 2.85 \\
\hline \multirow[t]{2}{*}{2014} & Mean & 835 & 5.49 & 0.09 & 150.52 & 117.68 & 813.85 & 66.44 & 20.07 \\
\hline & Std. Dev. & 438.6 & 1.17 & 0.03 & 66.35 & 86.56 & 353.14 & 24.35 & 3.20 \\
\hline \multirow[t]{2}{*}{2015} & Mean & 753 & 5.11 & 0.09 & 145.40 & 110.66 & 800.35 & 65.63 & 20.50 \\
\hline & Std. Dev. & 397.9 & 1.06 & 0.03 & 66.00 & 91.04 & 353.93 & 24.31 & 3.45 \\
\hline \multirow[t]{2}{*}{2016} & Mean & 742 & 5.18 & 0.09 & 142.62 & 102.50 & 793.15 & 64.61 & 20.83 \\
\hline & Std. Dev. & 389.1 & 0.99 & 0.02 & 65.91 & 74.22 & 354.58 & 24.28 & 3.42 \\
\hline \multirow[t]{2}{*}{2017} & Mean & 737 & 5.22 & 0.09 & 140.32 & 108.23 & 793.20 & 64.58 & 21.09 \\
\hline & Std. Dev. & 388.2 & 0.95 & 0.03 & 65.37 & 86.92 & 356.66 & 24.80 & 3.64 \\
\hline
\end{tabular}




\begin{tabular}{|c|c|c|c|c|c|c|c|c|}
\hline \multicolumn{2}{|l|}{ year } & English & Maths & Sciences & $\begin{array}{c}\text { Social } \\
\text { Sciences }\end{array}$ & Arts & $\begin{array}{c}\text { Modern } \\
\text { Languag } \\
\text { es }\end{array}$ & $\begin{array}{l}\text { Vocationa } \\
\text { I subjects }\end{array}$ \\
\hline \multirow[t]{2}{*}{2011} & Mean & 173.8 & 157.1 & 220.8 & 184.7 & 128.0 & 100.3 & 171.4 \\
\hline & Std. D. & 89.7 & 83.4 & 118.8 & 98.0 & 70.6 & 67.5 & 85.2 \\
\hline \multirow[t]{2}{*}{2012} & Mean & 176.2 & 155.3 & 218.7 & 185.1 & 127.4 & 94.9 & 167.7 \\
\hline & Std. D. & 92.1 & 84.9 & 118.3 & 103.0 & 70.9 & 66.1 & 85.3 \\
\hline \multirow[t]{2}{*}{2013} & Mean & 176.5 & 158.2 & 221.0 & 190.2 & 128.3 & 97.4 & 165.8 \\
\hline & Std. D. & 90.6 & 83.7 & 120.9 & 104.2 & 73.6 & 67.9 & 84.2 \\
\hline \multirow[t]{2}{*}{2014} & Mean & 135.0 & 105.6 & 173.1 & 144.1 & 95.0 & 51.6 & 130.1 \\
\hline & Std. D. & 70.9 & 56.4 & 101.6 & 85.7 & 57.4 & 43.1 & 69.2 \\
\hline \multirow[t]{2}{*}{2015} & Mean & 121.5 & 102.3 & 161.5 & 127.0 & 80.4 & 42.6 & 116.8 \\
\hline & Std. D. & 63.8 & 54.3 & 96.7 & 74.9 & 46.5 & 39.9 & 62.7 \\
\hline \multirow[t]{2}{*}{2016} & Mean & 119.9 & 109.1 & 158.5 & 123.8 & 77.6 & 39.6 & 113.4 \\
\hline & Std. D. & 61.3 & 56.6 & 96.4 & 71.0 & 45.6 & 38.0 & 60.4 \\
\hline \multirow[t]{2}{*}{2017} & Mean & 121.6 & 108.6 & 154.5 & 123.5 & 76.2 & 38.5 & 114.7 \\
\hline & Std. D. & 62.0 & 58.2 & 91.6 & 71.8 & 44.7 & 36.5 & 60.8 \\
\hline
\end{tabular}




\begin{tabular}{|c|c|c|c|c|c|c|c|c|}
\hline \multicolumn{2}{|l|}{ year } & English & Maths & Sciences & $\begin{array}{c}\text { Social } \\
\text { Sciences }\end{array}$ & Arts & $\begin{array}{c}\text { Modern } \\
\text { Languag } \\
\text { es }\end{array}$ & $\begin{array}{c}\text { Vocation } \\
\text { al } \\
\text { subjects } \\
\end{array}$ \\
\hline \multirow[t]{2}{*}{2011} & Mean & 15.3 & 13.9 & 16.0 & 19.2 & 11.2 & 8.5 & 15.8 \\
\hline & Std.D. & 3.2 & 3.5 & 3.4 & 3.9 & 3.1 & 3.4 & 5.1 \\
\hline \multirow[t]{2}{*}{2012} & Mean & 15.8 & 13.8 & 16.0 & 19.3 & 11.4 & 8.0 & 15.5 \\
\hline & Std.D. & 3.9 & 3.6 & 3.7 & 3.9 & 3.3 & 3.4 & 5.0 \\
\hline \multirow[t]{2}{*}{2013} & Mean & 15.8 & 14.0 & 16.3 & 19.2 & 11.2 & 8.2 & 15.2 \\
\hline & Std.D. & 3.7 & 3.4 & 3.7 & 4.1 & 3.1 & 3.5 & 4.9 \\
\hline \multirow[t]{2}{*}{2014} & Mean & 16.4 & 12.8 & 16.8 & 20.4 & 11.4 & 5.9 & 16.2 \\
\hline & Std.D. & 3.4 & 2.4 & 4.0 & 4.7 & 3.1 & 3.1 & 5.3 \\
\hline \multirow[t]{2}{*}{2015} & Mean & 16.3 & 13.6 & 16.4 & 21.1 & 10.8 & 5.4 & 16.2 \\
\hline & Std.D. & 3.2 & 2.8 & 3.9 & 4.4 & 3.2 & 3.1 & 5.4 \\
\hline \multirow[t]{2}{*}{2016} & Mean & 16.2 & 14.9 & 16.4 & 20.9 & 10.6 & 5.1 & 15.8 \\
\hline & Std.D. & 2.2 & 2.9 & 3.5 & 4.6 & 3.3 & 2.9 & 5.2 \\
\hline \multirow[t]{2}{*}{2017} & Mean & 16.6 & 14.6 & 16.6 & 20.5 & 10.5 & 4.8 & 16.4 \\
\hline & Std.D. & 2.6 & 2.6 & 3.9 & 4.1 & 3.1 & 2.7 & 6.8 \\
\hline
\end{tabular}




\begin{tabular}{|c|c|c|c|c|c|c|c|c|c|}
\hline $\begin{array}{l}\text { Dependent variable: } \\
\text { Average Number of } \\
\text { subject choices per } \$ 4 \\
\text { students }\end{array}$ & $\begin{array}{l}\text { Model (1) } \\
\text { Random } \\
\text { intercept only }\end{array}$ & \multicolumn{2}{|c|}{$\begin{array}{c}\text { Model (2) } \\
\text { Random } \\
\text { intercepts and } \\
\text { one covariate: } \\
\text { year1 }\end{array}$} & \multicolumn{2}{|c|}{$\begin{array}{l}\text { Model (3) } \\
\text { Random } \\
\text { intercepts and } \\
\text { one covariate: }\end{array}$} & \multicolumn{2}{|c|}{$\begin{array}{c}\text { Model (4) } \\
\text { Random slopes } \\
\text { and random } \\
\text { intercepts } \\
\text { model. } \\
\text { Covariates: } \\
\text { year-grouped } \\
\text { and SIMD } \\
\text { deprivation } \\
\text { decile }\end{array}$} & \multicolumn{2}{|c|}{$\begin{array}{c}\text { Model (5) } \\
\text { Random slopes } \\
\text { and random } \\
\text { intercepts model. } \\
\text { Contextual effects: } \\
\text { year-grouped, } \\
\text { deprivation decile; } \\
\text { school } \\
\text { characteristics }\end{array}$} \\
\hline \multicolumn{10}{|l|}{ Fixed Effects } \\
\hline \multicolumn{10}{|c|}{ Year $\quad 2011$ (reference category) } \\
\hline 2012 & & 0.068 & $(.08)$ & & & & & & \\
\hline 2013 & & 0.084 & (.08) & & & & & & \\
\hline 2014 & & -1.77 & (.08) & & & & & & \\
\hline 2015 & & -2.15 & $(.08)$ & & & & & & \\
\hline 2016 & & -2.08 & $(.08)$ & & & & & & \\
\hline 2017 & & -2.04 & (.08) & & & & & & \\
\hline \multicolumn{10}{|c|}{ Year grouped 2011-2013 (reference cat) } \\
\hline 2014 & & & & -1.81 & $(.09)$ & -1.82 & (.09) & -1.77 & (.09) \\
\hline $2015-2017$ & & & & -2.11 & (.13) & -2.12 & (.13) & -2.10 & (.14) \\
\hline \multicolumn{10}{|c|}{ SIMD Decile $\quad 1$ (reference cat) } \\
\hline 2 & & & & & & 0.06 & (.14) & -0.02 & (.13) \\
\hline 3 & & & & & & 0.34 & (.14) & 0.21 & $(.14)$ \\
\hline 4 & & & & & & 0.29 & (.15) & 0.16 & (.14) \\
\hline 5 & & & & & & 0.54 & $(.16)$ & 0.33 & (.15) \\
\hline 6 & & & & & & 0.58 & (.17) & 0.25 & (.16) \\
\hline 7 & & & & & & 0.77 & (.18) & 0.48 & (.16) \\
\hline 8 & & & & & & 0.60 & (.19) & 0.33 & (.18) \\
\hline 9 & & & & & & 0.84 & $(.20)$ & 0.53 & (.19) \\
\hline 10 (lowest deprivatic & & & & & & 0.90 & $(.22)$ & 0.41 & (.20) \\
\hline \multicolumn{10}{|c|}{ Rural/Urban Are Large urban areas(reference category) } \\
\hline Other urban areas & & & & & & & & 0.09 & (.09) \\
\hline Assessable small towns & & & & & & & & 0.19 & (.11) \\
\hline Other small towns & & & & & & & & -0.01 & (.11) \\
\hline Assessable rural & & & & & & & & 0.26 & (.13) \\
\hline Remote rural & & & & & & & & 0.56 & (.13) \\
\hline $\begin{array}{l}\text { Number of SCQF Level } \\
5 \text { subjects available in } \\
\text { S4 }\end{array}$ & & & & & & & & 0.05 & $(.01)$ \\
\hline Teachers/students ratio & & & & & & & & 0.60 & (.10) \\
\hline Students on free meals & & & & & & & & -0.004 & $(.00)$ \\
\hline $\begin{array}{l}\% \text { of students with add. } \\
\text { support needs }\end{array}$ & & & & & & & & -0.01 & $(.00)$ \\
\hline
\end{tabular}




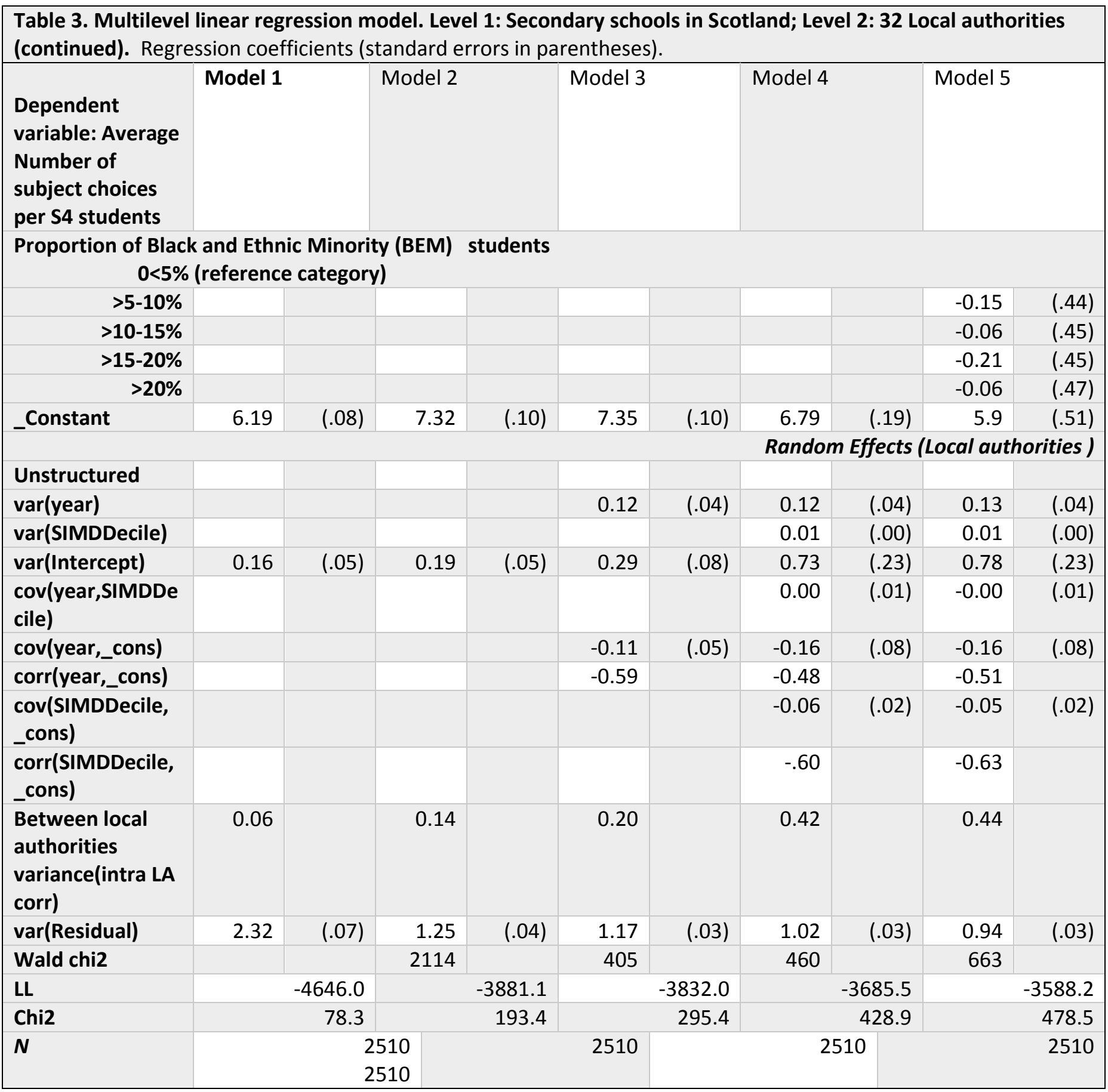




\begin{tabular}{|c|c|c|c|}
\hline \multicolumn{4}{|c|}{$\begin{array}{l}\text { Table 3.1 Results of full regression model for number of subject entries with Interaction effects }{ }^{25} \text { : } \\
\text { Interaction effect between year-grouped and schools area level of deprivation (deprivation } \\
\text { decile). Regression coefficients (standard errors in parentheses). }\end{array}$} \\
\hline & $\begin{array}{l}\text { Main effects } \\
(2011-2013)\end{array}$ & $\begin{array}{l}\text { Interaction effects } \\
\text { with year } 2014\end{array}$ & $\begin{array}{l}\text { Interaction effects } \\
\text { with years 2015-2017 }\end{array}$ \\
\hline \multicolumn{4}{|l|}{ Deprivation decile } \\
\hline Decile1 & - & $-1.40(.55)$ & $-1.68(.42)$ \\
\hline Decile 2 & $-0.20(.19)$ & $-0.85(.49)$ & $-1.36(.40)$ \\
\hline Decile 3 & $-0.00(.20)$ & $-0.98(.51)$ & $-1.32(.41)$ \\
\hline Decile 4 & $0.02(.20)$ & $-0.98(.48)$ & $-1.52(.40)$ \\
\hline Decile 5 & $0.11(.21)$ & $-0.72(.48)$ & $-1.44(.39)$ \\
\hline Decile 6 & $0.17(.21)$ & $-1.13(.50)$ & $-1.56(.39)$ \\
\hline Decile 7 & $0.37(.22)$ & $-1.06(.48)$ & $-1.60(.39)$ \\
\hline Decile 8 & $0.22(.23)$ & $-1.06(.50)$ & $-1.55(.39)$ \\
\hline Decile 9 & $0.42(.24)$ & $-1.01(.52)$ & $-1.61(.41)$ \\
\hline Decile 10 & $0.19(.25)$ & $-0.59(.52)$ & $-1.48(.41)$ \\
\hline \multicolumn{4}{|l|}{ Type of locality } \\
\hline $\begin{array}{l}\text { Large urban areas (reference } \\
\text { category) }\end{array}$ & - & $-0.27(.27)$ & $-0.04(.26)$ \\
\hline Other urban areas & $0.24(.13)$ & $-0.35(.27)$ & $-0.37(.22)$ \\
\hline Assessable small towns & $0.42(.15)$ & $-0.50(.29)$ & $-0.46(.23)$ \\
\hline Other small towns & $-0.08(.16)$ & $-0.19(.33)$ & $0.12(.25)$ \\
\hline Assessable rural & $0.37(.18)$ & $-0.28(.30)$ & $-0.31(.22)$ \\
\hline Remote rural & $0.50(.19)$ & - & - \\
\hline \multicolumn{4}{|l|}{ School characteristics } \\
\hline Teacher-student ratio & $0.05(.02)$ & $0.06(.03)$ & $0.019(.03)$ \\
\hline $\begin{array}{l}\text { Average number of subjects } \\
\text { available for National } 5 \\
\text { qualifications }\end{array}$ & $0.06(.01)$ & $-0.04(.03)$ & $-0.004(.02)$ \\
\hline $\begin{array}{l}\% \text { of students with special } \\
\text { needs }\end{array}$ & $-0.002(.00)$ & $-0.11(.1)$ & $-0.11(.0)$ \\
\hline $\begin{array}{l}\text { Number of students on free } \\
\text { school }\end{array}$ & $-0.003(.00)$ & $-0.002(.00)$ & $-0.003(.00)$ \\
\hline
\end{tabular}

\footnotetext{
${ }^{25}$ This regression model includes all covariates from Model 4 (see Table 3 ) as well as interaction effects between yeargrouped (the reference category is the period of 2011-2013. i.e. prior to the introduction of new qualifications). The table with all regression coefficients is available from authors on request.
} 


\begin{tabular}{|c|c|c|c|c|c|c|}
\hline \multirow{2}{*}{$\begin{array}{l}\text { Dependent variables: } \\
\text { Fixed effects } \\
\text { Year grouped reference category } 2011\end{array}$} & \multicolumn{2}{|c|}{$\begin{array}{l}\text { Model1. Percentage of } \\
\text { entries English }\end{array}$} & \multicolumn{2}{|c|}{$\begin{array}{l}\text { Model2. Percentage of } \\
\text { entries Maths }\end{array}$} & \multicolumn{2}{|c|}{$\begin{array}{l}\text { Model3. Percentage of } \\
\text { entries Sciences }\end{array}$} \\
\hline & & & & & & \\
\hline 2014 & 0.72 & $(.022)$ & -1.01 & $(.020)$ & 1.19 & $(.025)$ \\
\hline $2015-2017$ & 0.69 & $(.027)$ & 0.55 & $(.020)$ & 1.56 & (.028) \\
\hline \multicolumn{7}{|c|}{ SIMD Decile ( Reference category: decile 1) } \\
\hline decile 2 & 0.38 & $(.039)$ & 0.22 & $(.040)$ & 0.89 & (.048) \\
\hline decile 3 & -0.10 & $(.041)$ & -0.35 & $(.040)$ & 1.04 & $(.052)$ \\
\hline decile 4 & -0.54 & $(.041)$ & -0.49 & $(.040)$ & 1.52 & (.054) \\
\hline decile 5 & -0.28 & $(.044)$ & 0.067 & $(.040)$ & 2.21 & (.059) \\
\hline decile 6 & -0.03 & $(.045)$ & 0.48 & $(.040)$ & 1.80 & (.062) \\
\hline decile 7 & -0.19 & $(.047)$ & 0.11 & $(.050)$ & 1.35 & (.067) \\
\hline decile 8 & -0.25 & $(.050)$ & 0.37 & $(.050)$ & 1.32 & (.073) \\
\hline decile 9 & -0.55 & $(.053)$ & 0.65 & $(.051)$ & 1.27 & $(.079)$ \\
\hline (Lowest deprivation) decile 10. & -0.19 & $(.057)$ & 0.76 & $(.054)$ & 2.4 & $(.085)$ \\
\hline \multicolumn{7}{|c|}{ Rural/Urban Area reference category Large urban areas } \\
\hline Other urban areas & 0.001 & $(.025)$ & -0.20 & $(.025)$ & -0.35 & $(.033)$ \\
\hline Assessable small towns & -0.06 & $(.031)$ & -0.38 & $(.030)$ & 0.42 & (.039) \\
\hline Other small towns & -0.01 & $(.034)$ & -0.28 & $(.033)$ & 0.19 & (.042) \\
\hline Assessable rural & -0.32 & $(.036)$ & 0.09 & $(.035)$ & 0.47 & $(.047)$ \\
\hline Remote rural & -0.28 & $(.037)$ & -0.49 & $(.036)$ & 1.19 & (.046) \\
\hline Teachers/students ratio & -0.03 & $(.003)$ & 0.04 & $(.003)$ & 0.32 & (.000) \\
\hline Students on free meals & 0.004 & $(.001)$ & -0.004 & $(.000)$ & -0.015 & (.000) \\
\hline$\%$ of students with special needs & 0.009 & $(.001)$ & 0.00 & $(.001)$ & -0.013 & (.001) \\
\hline Proportion of BEM Reference category & $0<5 \%$ & & & & & \\
\hline$>5-10 \%$ & 2.53 & (1.40) & -2.3 & (1.37) & -1.02 & (1.63) \\
\hline$>10-15 \%$ & 2.64 & $(1.40)$ & -2.4 & (1.37) & -0.45 & (1.64) \\
\hline$>15-20 \%$ & 2.42 & $(1.42)$ & -2.6 & (1.38) & -0.42 & (1.66) \\
\hline$>20 \%$ & 2.88 & $(1.44)$ & -2.2 & $(1.40)$ & 0.69 & (1.68) \\
\hline _Constant & 13.0 & (1.63) & 16.2 & (1.57) & 17.3 & (1.81) \\
\hline \multicolumn{7}{|l|}{ Random Effects (Variance Unstructured) } \\
\hline $\operatorname{var}($ year) & 0.38 & $(.014)$ & 0.26 & $(.011)$ & 0.30 & $(.014)$ \\
\hline var(SIMDDecile) & 0.05 & $(.002)$ & 0.04 & $(.002)$ & 0.16 & $(.006)$ \\
\hline $\operatorname{var}\left(\_\right.$constant) & 4.24 & (1.48) & 2.22 & $(.091)$ & 8.06 & (3.12) \\
\hline $\operatorname{cov}($ year,SIMDDecile) & 0.03 & $(.004)$ & 0.02 & $(.003)$ & -0.03 & $(.006)$ \\
\hline cov(year,_cons) & -0.94 & $(.039)$ & -0.40 & $(.026)$ & -0.08 & $(.048)$ \\
\hline corr(year,_cons) & -0.74 & & -0.5 & & 0.01 & \\
\hline cov(SIMDDecile,_cons) & -0.35 & $(.015)$ & -0.26 & $(.013)$ & -1.04 & $(.041)$ \\
\hline corr(SIMDDecile,_cons) & -0.76 & & -0.83 & & -0.65 & \\
\hline $\begin{array}{l}\text { Between local authorities variance } \\
\text { (intra LA correlation) }\end{array}$ & 0.32 & & 0.22 & & 0.41 & \\
\hline $\operatorname{var(Residual)}$ & 8.95 & $(.026)$ & 8.70 & $(.025)$ & 13.09 & $(.38)$ \\
\hline Wald chi2 & 54.57 & & 111.47 & & 256.57 & \\
\hline LL & -6387.70 & & -6327.13 & & -6852.94 & \\
\hline Chi2 & 174.83 & & 105.66 & & 253.00 & \\
\hline N & 2515 & & 2515 & & 2515 & \\
\hline
\end{tabular}


Table 5. Multilevel linear regressions with random slopes and random intercepts for year and privation decile. Regression coefficients (standard errors on parentheses). Contextual effects: year-grouped, deprivation decile; school characteristics

\begin{tabular}{|c|c|c|c|c|c|c|c|c|}
\hline $\begin{array}{l}\text { Dependent variables: } \\
\text { Fixed Effects }\end{array}$ & \multicolumn{2}{|c|}{$\begin{array}{c}\text { Model4. } \\
\text { Percentage of } \\
\text { entries: Social } \\
\text { Subjects }\end{array}$} & \multicolumn{2}{|c|}{$\begin{array}{c}\text { Model5. } \\
\text { Percentage of } \\
\text { entries: Modern } \\
\text { Languages }\end{array}$} & \multicolumn{2}{|c|}{$\begin{array}{c}\text { Model6. } \\
\text { Percentage of } \\
\text { entries: Vocational } \\
\text { subjects }\end{array}$} & \multicolumn{2}{|c|}{$\begin{array}{c}\text { Model7. } \\
\text { Percentage of } \\
\text { entries: Arts }\end{array}$} \\
\hline \multicolumn{9}{|c|}{ 2011-2013(reference category)Year grouped: Reference category: 2011-2013 } \\
\hline 2014 & 0.79 & $(.023)$ & -2.08 & $(.021)$ & 0.39 & $(.032)$ & 0.073 & $(.020)$ \\
\hline 2015-2017 & 0.57 & $(.024)$ & -2.80 & $(.029)$ & 0.27 & $(.036)$ & -0.69 & $(.022)$ \\
\hline \multicolumn{9}{|c|}{ SIMD Decile Reference category: decile 1) } \\
\hline decile 2 & 0.19 & $(.045)$ & 0.25 & $(.037)$ & -1.23 & $(.062)$ & -0.46 & $(.039)$ \\
\hline decile 3 & 0.74 & $(.047)$ & 0.33 & $(.040)$ & -1.23 & $(.066)$ & -0.33 & $(.041)$ \\
\hline decile 4 & 0.94 & $(.048)$ & 0.015 & $(.042)$ & -0.88 & $(.068)$ & -0.48 & $(.042)$ \\
\hline decile 5 & 0.60 & $(.051)$ & 0.36 & $(.046)$ & -2.63 & $(.073)$ & -0.18 & $(.046)$ \\
\hline decile 6 & 0.45 & $(.054)$ & -0.049 & $(.049)$ & -2.51 & $(.077)$ & -0.065 & $(.048)$ \\
\hline decile 7 & 1.34 & $(.057)$ & -0.071 & $(.053)$ & -2.62 & $(.082)$ & 0.12 & $(.051)$ \\
\hline decile 8 & 0.63 & $(.061)$ & -0.46 & $(.058)$ & -1.86 & $(.089)$ & 0.12 & $(.055)$ \\
\hline decile 9 & 1.56 & (.065) & -0.53 & $(.063)$ & -2.88 & $(.096)$ & 0.22 & (.059) \\
\hline (lowest deprivation) decile 10 & 1.28 & $(.071)$ & -0.36 & $(.069)$ & -4.02 & $(1.04)$ & -0.090 & $(.064)$ \\
\hline \multicolumn{9}{|c|}{ Rural/Urban Area (Reference category: Large urban areas) } \\
\hline Other urban areas & 0.40 & $(.031)$ & -0.27 & $(.026)$ & -0.21 & $(.042)$ & 0.45 & $(.026)$ \\
\hline Assessable small towns & -0.65 & $(.036)$ & -0.34 & $(.030)$ & -0.53 & $(.049)$ & 0.96 & $(.031)$ \\
\hline Other small towns & -0.22 & $(.039)$ & -0.03 & $(.032)$ & -0.017 & $(.053)$ & 0.021 & $(.034)$ \\
\hline Assessable rural & -0.60 & $(.043)$ & -0.95 & $(.036)$ & 0.58 & $(.058)$ & 0.46 & $(.037)$ \\
\hline Remote rural & 0.52 & $(.044)$ & 0.48 & $(.037)$ & -1.92 & $(.059)$ & 0.091 & $(.038)$ \\
\hline Teachers/students ratio & 0.23 & $(.004)$ & 0.11 & $(.003)$ & -0.51 & $(.005)$ & -0.20 & $(.003)$ \\
\hline Students on free meals & -0.00 & $(.000)$ & -0.01 & $(.000)$ & 0.018 & $(.000)$ & 0.01 & $(.000)$ \\
\hline$\%$ of students with special needs & -0.005 & $(.001)$ & -0.05 & $(.001)$ & 0.046 & $(.001)$ & -0.001 & $(.001)$ \\
\hline \multicolumn{9}{|c|}{ Proportion of BEM students $\quad$ Reference category: $0<5 \%$} \\
\hline$>5-10 \%$ & 1.34 & $(1.54)$ & -0.87 & (1.24) & -0.76 & (2.10) & 1.22 & (1.33) \\
\hline$>10-15 \%$ & 1.08 & (1.54) & -0.45 & (1.25) & -1.32 & $(2.11)$ & 0.92 & (1.33) \\
\hline$>15-20 \%$ & 1.12 & (1.56) & -0.44 & $(1.26)$ & -0.63 & $(2.13)$ & 0.60 & (1.35) \\
\hline$>20 \%$ & 0.93 & (1.58) & -0.016 & (1.28) & -3.48 & (2.16) & 1.39 & (1.37) \\
\hline _Constant & 11.71 & $(1.67)$ & 9.54 & $(1.41)$ & 21.67 & $(2.32)$ & 11.11 & $(1.46)$ \\
\hline \multicolumn{9}{|l|}{ Random Effects } \\
\hline var(year) & 0.18 & $(.010)$ & 0.50 & $(.016)$ & 0.55 & $(.022)$ & 0.17 & $(.008)$ \\
\hline $\operatorname{var(SIMDDecile)}$ & 0.09 & $(.003)$ & 0.11 & $(.004)$ & 0.23 & $(.009)$ & 0.08 & $(.003)$ \\
\hline var(_constant) & 3.44 & (1.49) & 7.92 & $(2.50)$ & 13.6 & $(4.70)$ & 4.77 & (1.70) \\
\hline cov(year,SIMDDecile) & -0.02 & $(.004)$ & 0.01 & $(.005)$ & -0.10 & $(.010)$ & -0.04 & $(.004)$ \\
\hline cov(year,_cons) & -0.11 & $(.027)$ & -0.64 & $(.047)$ & -0.31 & $(.071)$ & -0.01 & $(.026)$ \\
\hline cor(year,_cons) & -0.06 & & -0.23 & & -0.11 & & -0.01 & \\
\hline cov(SIMDDecile,_cons) & -0.38 & $(.021)$ & -0.78 & (.039) & -1.50 & $(.060)$ & -0.53 & $(.022)$ \\
\hline corr(SIMDDecile,_cons) & -0.69 & & -0.84 & & -0.84 & & -0.85 & \\
\hline $\begin{array}{l}\text { Between local authorities variance } \\
\text { (intra LA correlation) }\end{array}$ & 0.24 & & 0.51 & & 0.36 & & 0.36 & \\
\hline var(Residual) & 11.4 & $(.032)$ & 7.36 & $(.021)$ & 21.28 & $(.060)$ & 8.46 & $(.024)$ \\
\hline Wald chi2 & 125.2 & & 287.8 & & 268.6 & & 110.5 & \\
\hline LL & -6699.6 & & -6180.5 & & -7476.2 & & -6324.3 & \\
\hline Chi2 & 228.0 & & 441.1 & & 207.0 & & 193.7 & \\
\hline$N$ & 2515 & & 2515 & & 2515 & & 2515 & \\
\hline
\end{tabular}




\section{Appendix 1. Subject groups}

Table A1.

\begin{tabular}{|c|c|c|c|c|c|c|c|}
\hline English & $\begin{array}{l}\text { Modern } \\
\text { languages }\end{array}$ & $\begin{array}{l}\text { Classical/ } \\
\text { other } \\
\text { languages }\end{array}$ & Maths & Science Subjects & $\begin{array}{l}\text { Social } \\
\text { subjects }\end{array}$ & $\begin{array}{l}\text { Applied } \\
\text { subjects }\end{array}$ & Arts \\
\hline $\begin{array}{l}\text { English; } \\
\text { English for } \\
\text { Speakers of } \\
\text { other } \\
\text { languages }\end{array}$ & $\begin{array}{l}\text { French; } \\
\text { German; } \\
\text { Italian; } \\
\text { Spanish; } \\
\text { Russian; } \\
\text { Gaelic } \\
\text { (Learners); } \\
\text { Gàidhlig; } \\
\text { Urdu; } \\
\text { Chinese; } \\
\text { Languages. }\end{array}$ & $\begin{array}{l}\text { Classical } \\
\text { Greek; } \\
\text { Latin; } \\
\text { Classical } \\
\text { Studies. }\end{array}$ & $\begin{array}{l}\text { Maths } \\
\text { Lifeskills } \\
\text { Maths }\end{array}$ & $\begin{array}{l}\text { Biology; } \\
\text { Bio-technology; } \\
\text { Human } \\
\text { biology; } \\
\text { Chemistry; } \\
\text { Physics; } \\
\text { Computing; } \\
\text { Environmental } \\
\text { Science; } \\
\text { Electronic and } \\
\text { Electrical } \\
\text { Fundamentals; } \\
\text { Engineering; } \\
\text { Information } \\
\text { Systems; } \\
\text { Technological } \\
\text { Studies; } \\
\text { Technology; } \\
\text { Practical } \\
\text { Electronics; } \\
\text { Applied Practical } \\
\text { Electronics; } \\
\text { Electrical } \\
\text { Installation } \\
\text { Fundamentals; } \\
\text { Engineering } \\
\text { Science; } \\
\text { Geology }\end{array}$ & $\begin{array}{l}\text { Geography; } \\
\text { History; } \\
\text { Psychology; } \\
\text { Religious, } \\
\text { Moral and } \\
\text { Philosophic } \\
\text { al Studies; } \\
\text { Sociology; } \\
\text { Economics; } \\
\text { Media } \\
\text { Studies; } \\
\text { Modern } \\
\text { Studies; } \\
\text { Philosophy; } \\
\text { Managing } \\
\text { Environ- } \\
\text { mental } \\
\text { Resources; } \\
\text { Accounting; } \\
\text { Administ- } \\
\text { ration; } \\
\text { Administ- } \\
\text { ration and } \\
\text { IT Business } \\
\text { Manage- } \\
\text { ment. }\end{array}$ & $\begin{array}{l}\text { Design and } \\
\text { Manufacture; } \\
\text { Care; } \\
\text { Craft } \\
\text { Skills; } \\
\text { Fashion and } \\
\text { Textile } \\
\text { Technology; } \\
\text { Health and } \\
\text { Food } \\
\text { Technology; } \\
\text { Home } \\
\text { economics; } \\
\text { Hospitality; } \\
\text { Physical } \\
\text { Education; } \\
\text { Practical } \\
\text { Metal- } \\
\text { working; } \\
\text { Product } \\
\text { Design; } \\
\text { Selling } \\
\text { Overseas; } \\
\text { Tourist } \\
\text { Destinations; } \\
\text { Travel and } \\
\text { Tourism; } \\
\text { Wood- } \\
\text { working } \\
\text { Skills; } \\
\text { Practical } \\
\text { Wood- } \\
\text { working. }\end{array}$ & $\begin{array}{l}\text { Art and } \\
\text { Design; } \\
\text { Dance; } \\
\text { Drama; } \\
\text { Music; } \\
\text { Graphic } \\
\text { Commu- } \\
\text { nication. }\end{array}$ \\
\hline
\end{tabular}




\section{Appendix 2.}

\section{Regression diagnostics}

Figure A2.a. Predicted( fitted) values vs ovserved Figure A2.b. Fixed part vs random part of the values of numver of sybject chocies predicted values of nimber of subject choices

a. Model 5

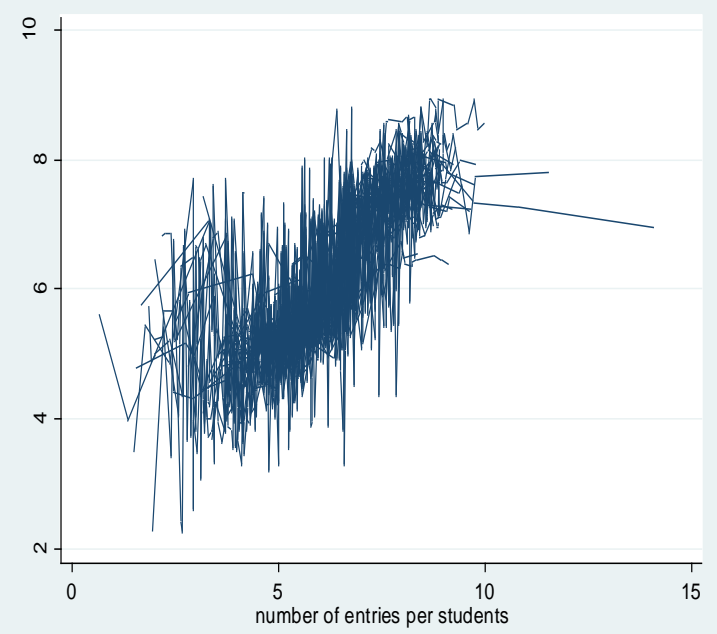

b. Model 5

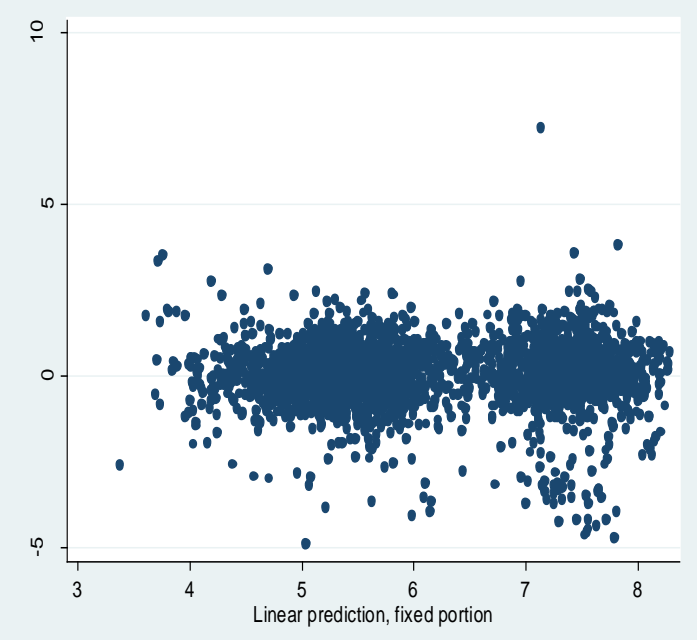




\section{Figure A2.c.}

Number of subject choices by year, observed values

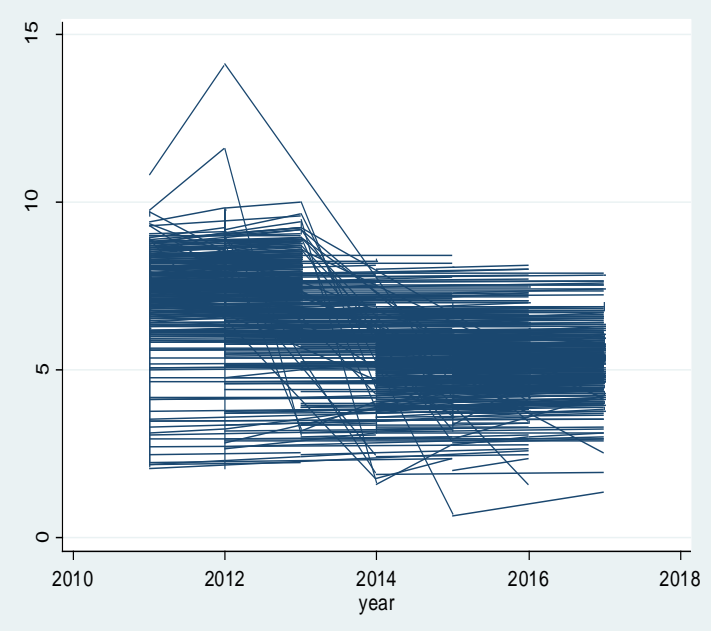

Figure A2.e.

Number of subject choices by deprivation decile, observed values

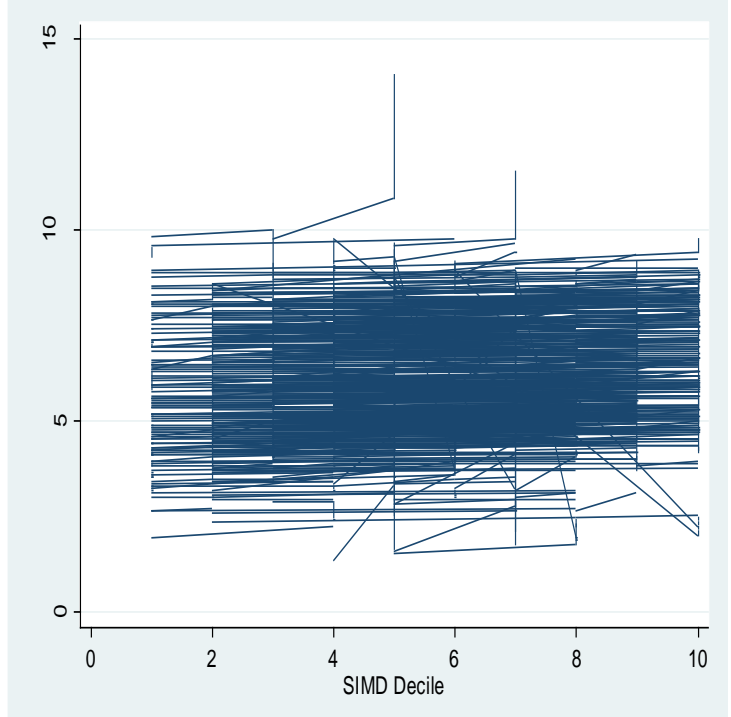

\section{Figure A2.d}

Number of subject choices by year, predicted values (model 5 from Table 3)

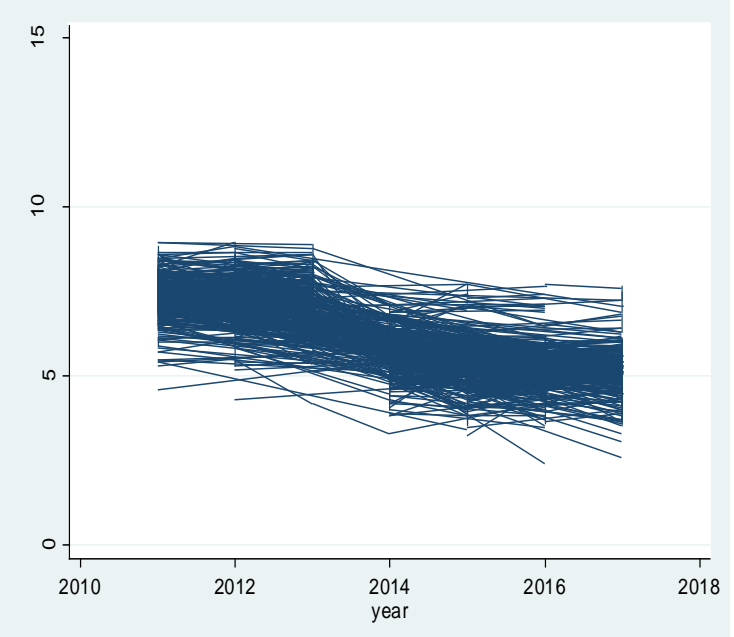

Figure A2.f.

Number of subject choices by deprivation decile, predicted vales values (model 5 from Table 3)

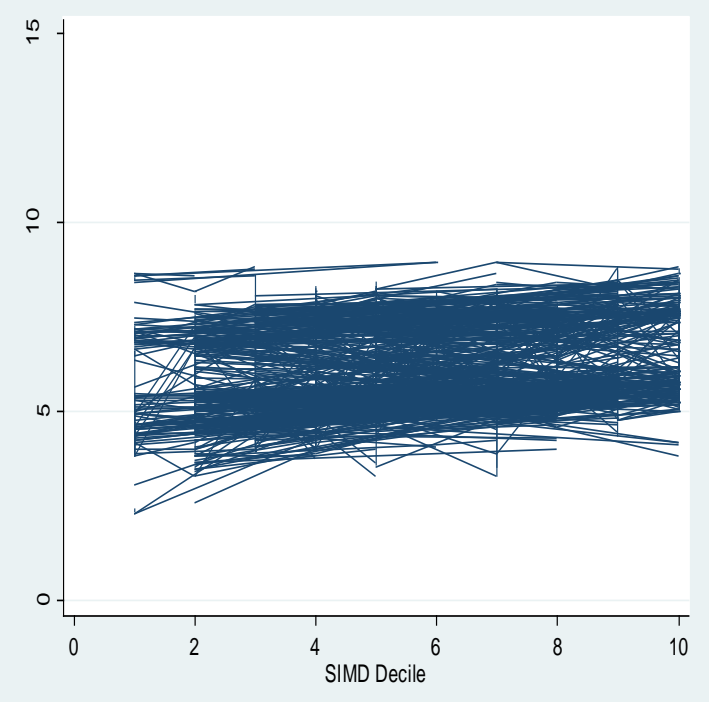




\section{Appendix 3}

Table A3.1 Multilevel linear model of the average number of subject entries per students, controlling for the S4 roll size. Level 1: Secondary schools in Scotland; Level 2: 32 Local authorities

\begin{tabular}{|c|c|c|}
\hline & b & Std.err. \\
\hline 2011-2013 (reference category) & - & \\
\hline 2014 & -1.76 & $(.009)$ \\
\hline 2015 onwards & -2.10 & $(.014)$ \\
\hline 1.SIMDDecile(reference category) & - & \\
\hline 2.SIMDDecile & 0.013 & $(.013)$ \\
\hline 3.SIMDDecile & 0.22 & $(.014)$ \\
\hline 4.SIMDDecile & 0.18 & $(.014)$ \\
\hline 5.SIMDDecile & 0.36 & $(.015)$ \\
\hline 6.SIMDDecile & 0.27 & $(.016)$ \\
\hline 7.SIMDDecile & 0.50 & $(.016)$ \\
\hline 8.SIMDDecile & 0.35 & $(.018)$ \\
\hline 9.SIMDDecile & 0.55 & $(.019)$ \\
\hline 10.SIMDDecile & 0.45 & $(.020)$ \\
\hline Rural/Urban Are Large urban areas (reference category) & - & \\
\hline Other urban areas & 0.092 & $(.009)$ \\
\hline Assessable small towns & 0.18 & $(.011)$ \\
\hline Other small towns & -0.013 & $(.011)$ \\
\hline Assessable rural & 0.26 & $(.013)$ \\
\hline Remote rural & 0.51 & $(.013)$ \\
\hline Number of SCQF Level 5 subjects available in S4 & 0.06 & $(.001)$ \\
\hline Students on Free Meals & -0.004 & $(.000)$ \\
\hline$\%$ of students with additional support needs & -0.01 & $(.000)$ \\
\hline Size of the 54 roll & 0.002 & $(.000)$ \\
\hline $\begin{array}{l}\text { Proportion of Black and Ethnic Minority students } 0<5 \% \text { (reference } \\
\text { category) }\end{array}$ & - & \\
\hline$>5-10 \%$ & -0.13 & $(.045)$ \\
\hline$>10-15 \%$ & -0.033 & $(.045)$ \\
\hline$>15-20 \%$ & 0.25 & $(.045)$ \\
\hline$>20 \%$ & 0.096 & $(.046)$ \\
\hline Constant & 6.07 & $(.052)$ \\
\hline \multicolumn{3}{|l|}{ Random effects (Local authorities) Unstructured } \\
\hline var(year) & 0.13 & $(.004)$ \\
\hline var(SIMDDecile) & 0.007 & $(.0002)$ \\
\hline $\operatorname{var}($ Intercept) & 0.78 & $(.023)$ \\
\hline $\operatorname{cov}($ year,SIMDDecile) & -0.007 & $(.001)$ \\
\hline cov(year,_cons) & -0.16 & $(.008)$ \\
\hline cov(SIMDDecile,_cons) & -0.05 & $(.002)$ \\
\hline Chi2(6) & 500 & $(.000)$ \\
\hline
\end{tabular}


Appendix 4. Martiros Saryan's Matriculation Certificates and Qualifications ${ }^{26}$ at age 15

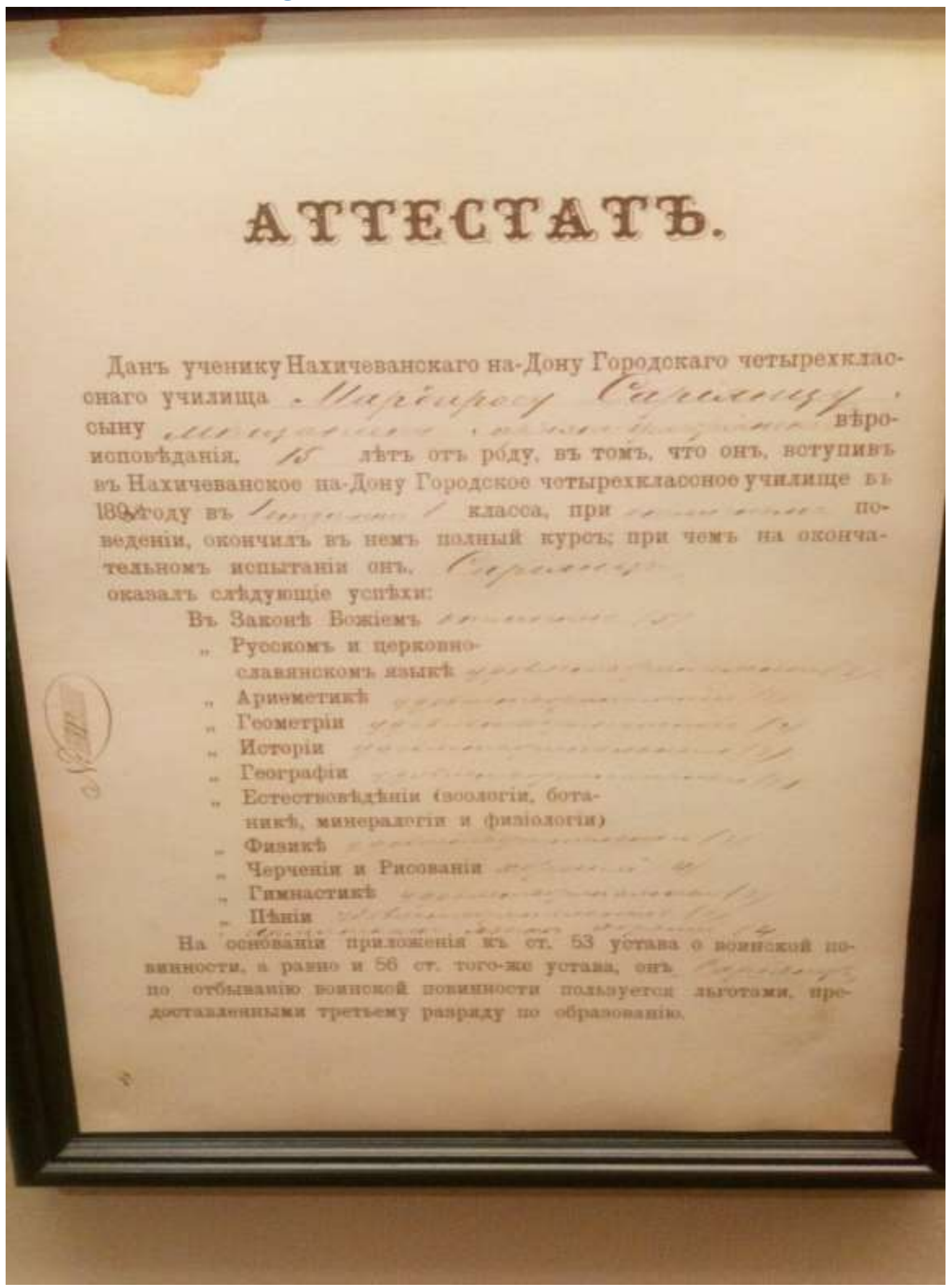

${ }^{26}$ Translation: Matriculation Certificate. Gi Translation: Matriculation Certificate. Given to the pupil of Nakhichevan-onDon four year college Martiros Saryan, Parental origin- middle class; religion - Armenian, age -15, to certify that that 
Translation of the document on page 41:

Matriculation Certificate.

Issued to the pupil of the Nakhichevan-on-Don four-year college, Martiros Saryan, son of a petty bourgeois of Armenian religion, 15 years of age, to certify that that he was admitted to the Nakhichevan-on-Don fouryear college in 1891 to the class and graduated it with demonstrating exemplary behaviour and has shown the following achievements during his final tests:

Religion - excellent;

Russian and Church-Slavic languages - satisfactory;

Arithmetic -- satisfactory;

Geometry - satisfactory;

History - satisfactory;

Geography - satisfactory;

Natural Sciences (Zoology, Botanic, Mineralogy and Physiology) - satisfactory;

Physics - satisfactory;

Painting and Technical Drawing - good;

Physical Education - satisfactory;

Music - satisfactory.

Armenian language - good. 


\section{Appendix 5}

Table A5.1 Scottish Credit and Qualification Framework (SCQF) ${ }^{27}$ :

\begin{tabular}{|c|c|c|c|c|}
\hline SCQF levels & $\begin{array}{l}\text { SQA National } \\
\text { Units, courses } \\
\text { and group } \\
\text { awards }\end{array}$ & $\begin{array}{l}\text { Higher Education } \\
\text { (HE) } \\
\text { qualifications }\end{array}$ & $\begin{array}{l}\text { Scottish } \\
\text { Vocational } \\
\text { Qualifications }\end{array}$ & SCQF levels \\
\hline 12 & & Doctorate & & 12 \\
\hline 11 & & Masters & SVQ 5 & 11 \\
\hline 10 & & Honours degree & & 10 \\
\hline 9 & & Ordinary degree & & 9 \\
\hline \multirow[t]{2}{*}{8} & & HND & SVQ 4 & 8 \\
\hline & & Diploma of HE & & \\
\hline \multirow[t]{2}{*}{7} & Advanced Higher & $\mathrm{HNC}$ & & 7 \\
\hline & & Certificate of $\mathrm{HE}$ & & \\
\hline 6 & Higher & & SVQ 3 & 6 \\
\hline \multirow[t]{2}{*}{5} & Intermediate 2/ & & SVQ 2 & 5 \\
\hline & $\begin{array}{l}\text { Credit Standard } \\
\text { Grade }\end{array}$ & & & \\
\hline 4 & $\begin{array}{l}\text { Intermediate 1/ } \\
\text { General Standard } \\
\text { Grade }\end{array}$ & & SVQ 1 & 4 \\
\hline 3 & $\begin{array}{l}\text { Access 3/ } \\
\text { Foundation S } \\
\text { Grade }\end{array}$ & & & 3 \\
\hline 2 & Access 2 & & & 2 \\
\hline 1 & Access 1 & & & 1 \\
\hline
\end{tabular}

${ }^{27}$ https://news.gov.scot/speeches-and-briefings/new-national-qualifications-summary-information 
Figures 
Figure 1. Characteristics of subject's choices and school characteristics by year (boxplots).
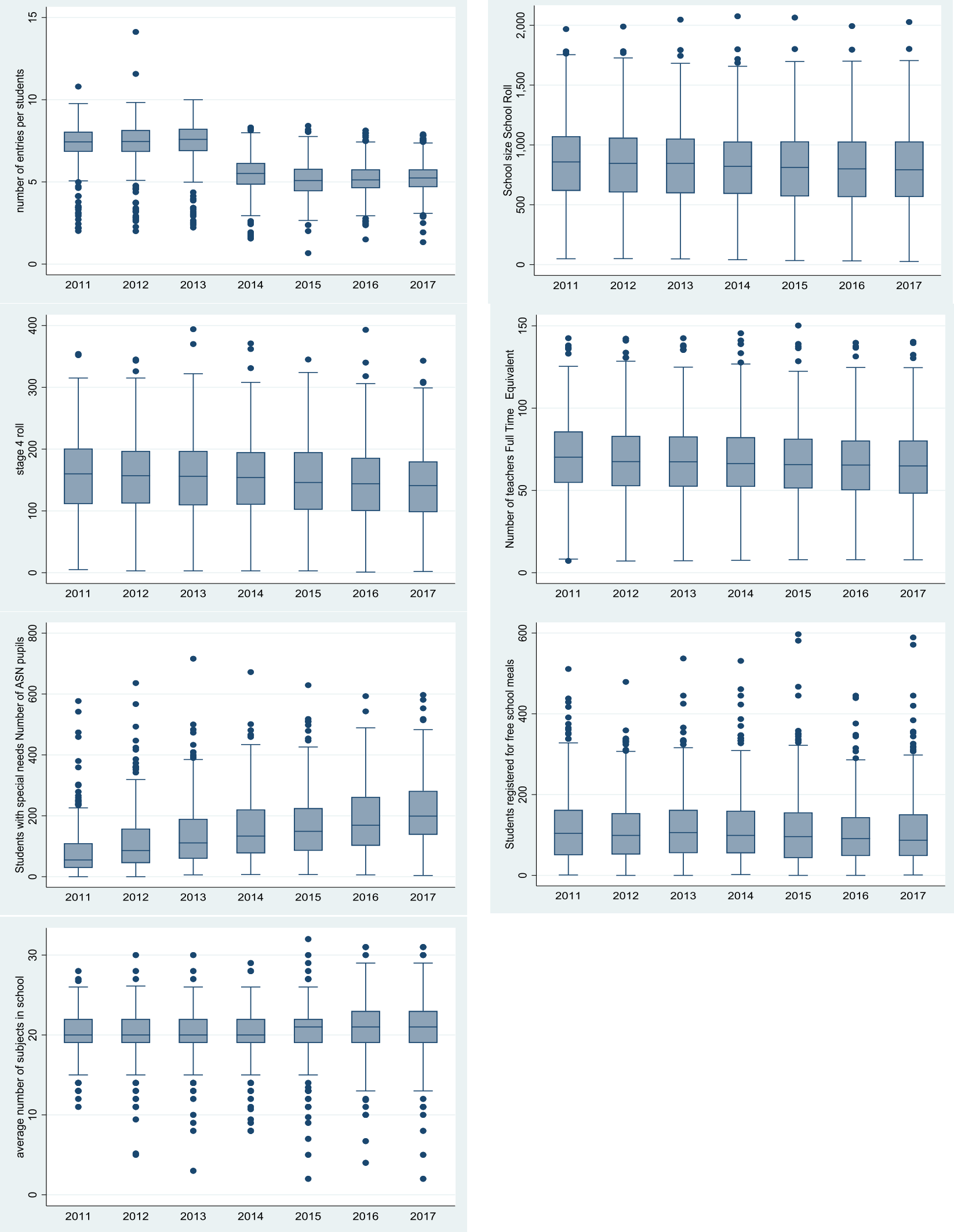
Figure 2. Trends in number of subject choices per student in S4 at SCQF level 5 by 1) by level of school area deprivation(SIMD Decile); 2) by Local Authority
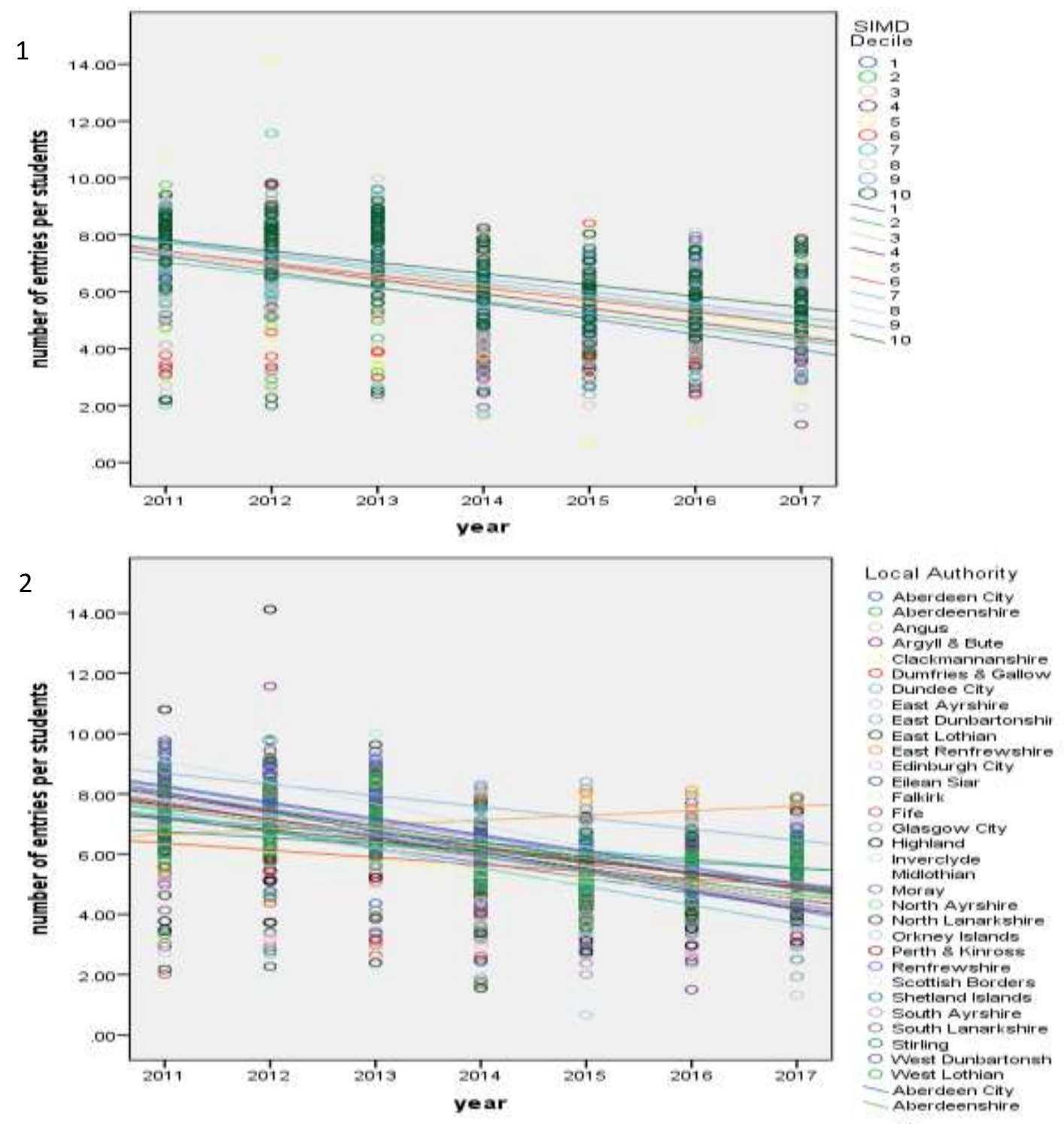
Figure 3. Trends in number of subjects available for students in S4 at SCQF level 5 by 1) level of school area deprivation (SIMD Decile); 2) by Local Authority
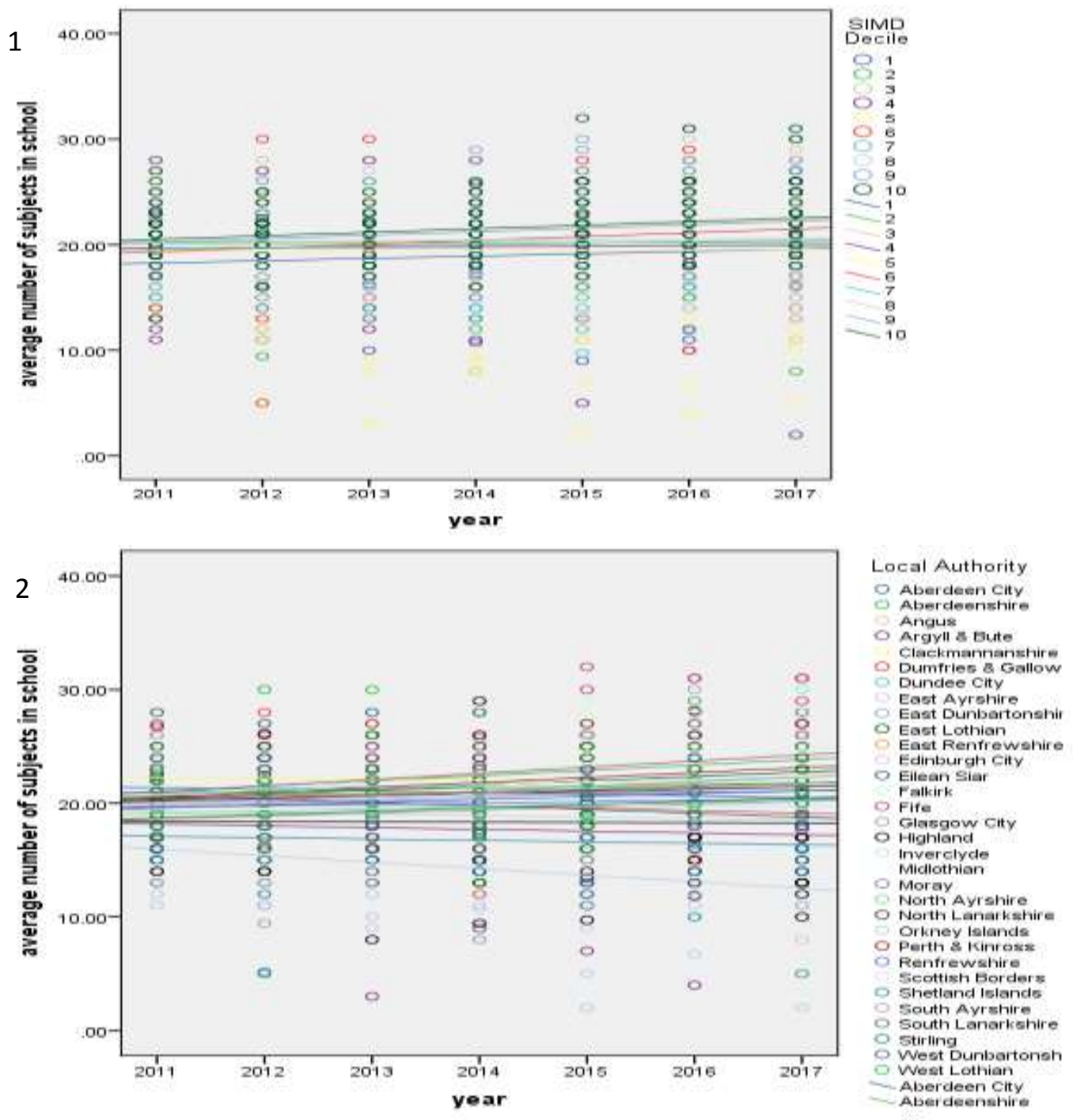
Figure 4a. Trends in relative subject intakes for National 5 qualifications in S4: English, Maths, Science 1

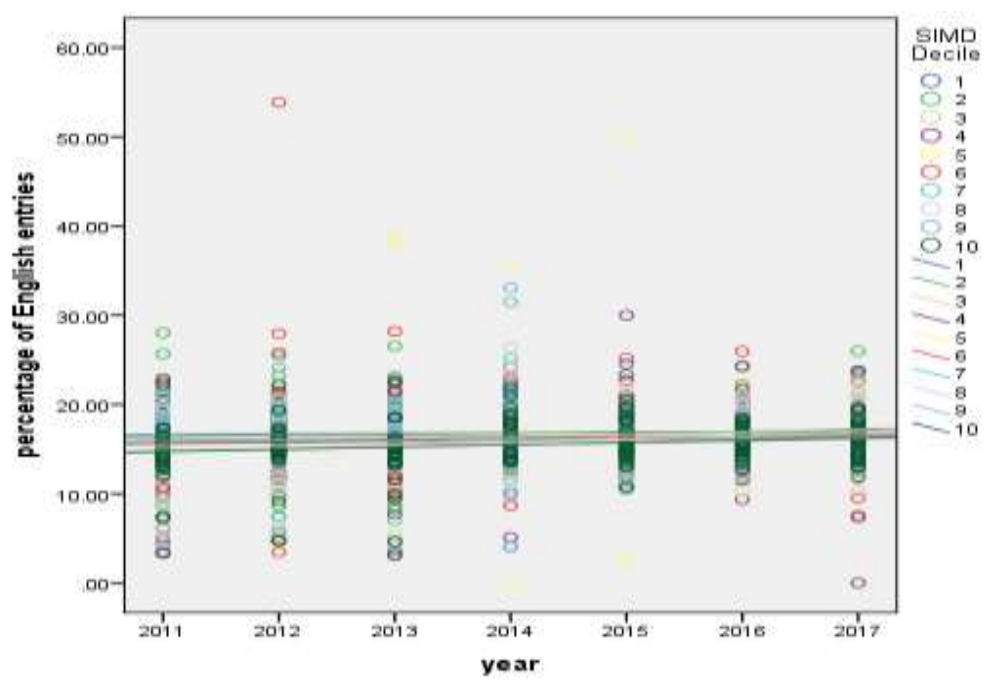

2

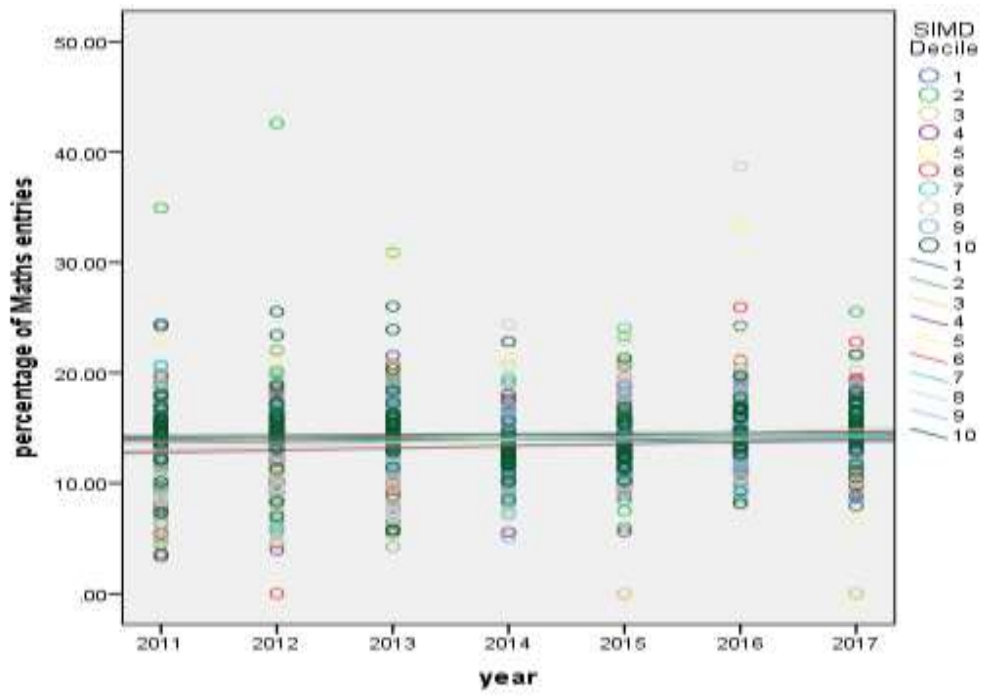

3

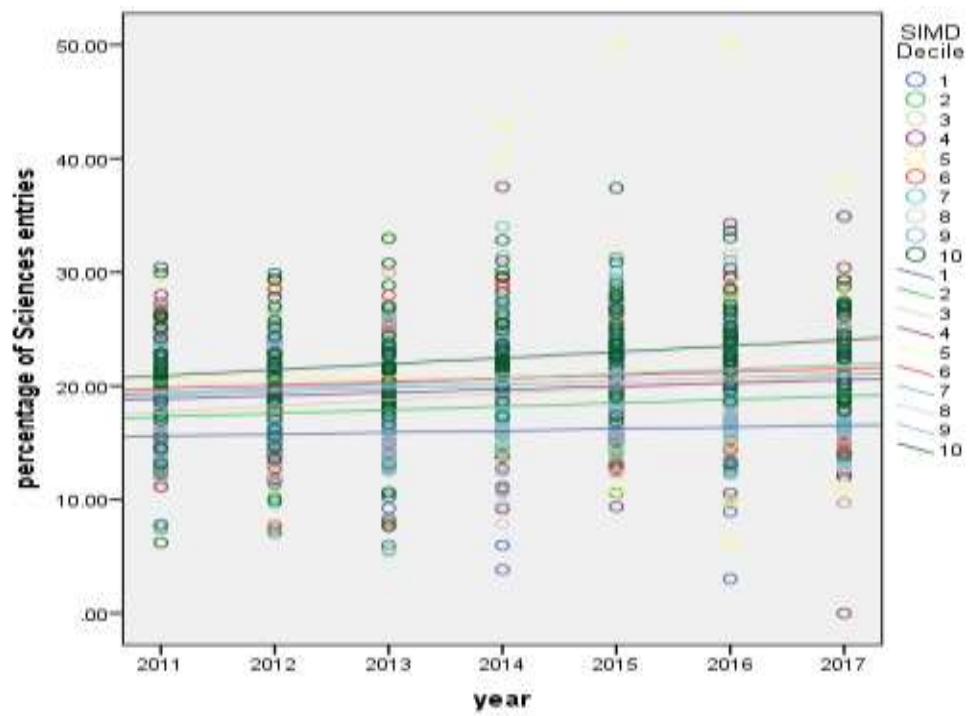


Figure 4b. Trends in relative of subject intakes for National 5 qualifications in S4: Modern Languages, Arts and Modern Languages

1

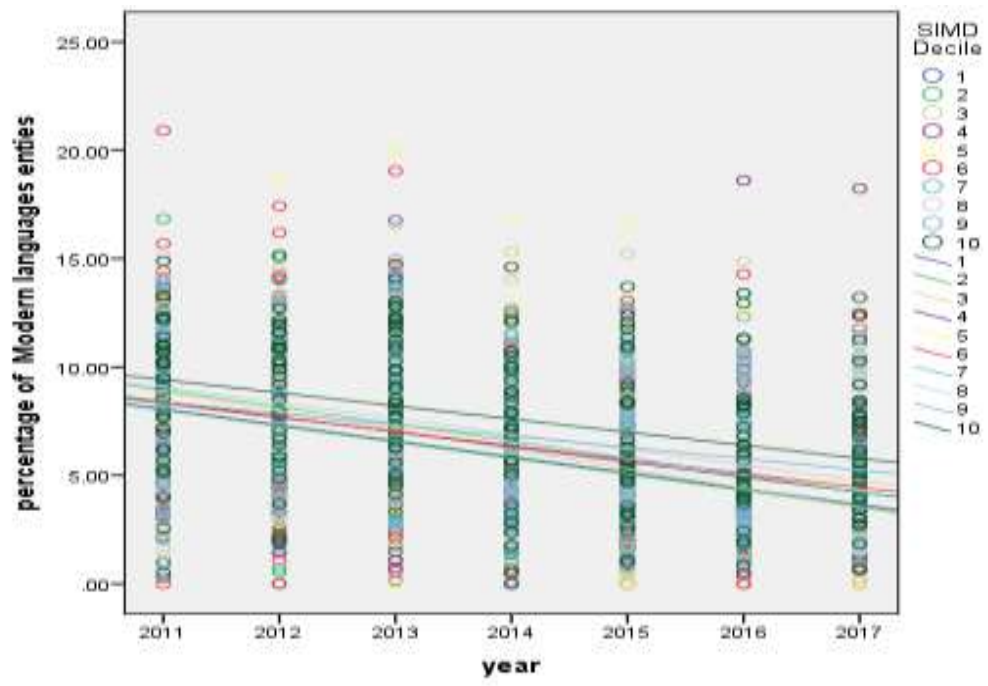

2

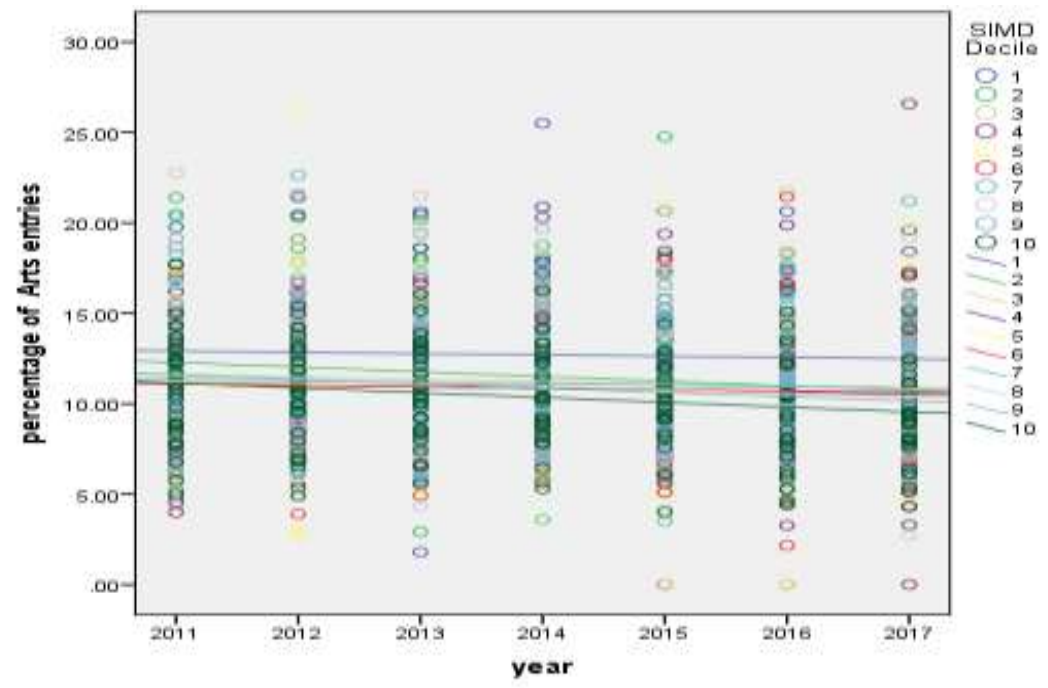

3

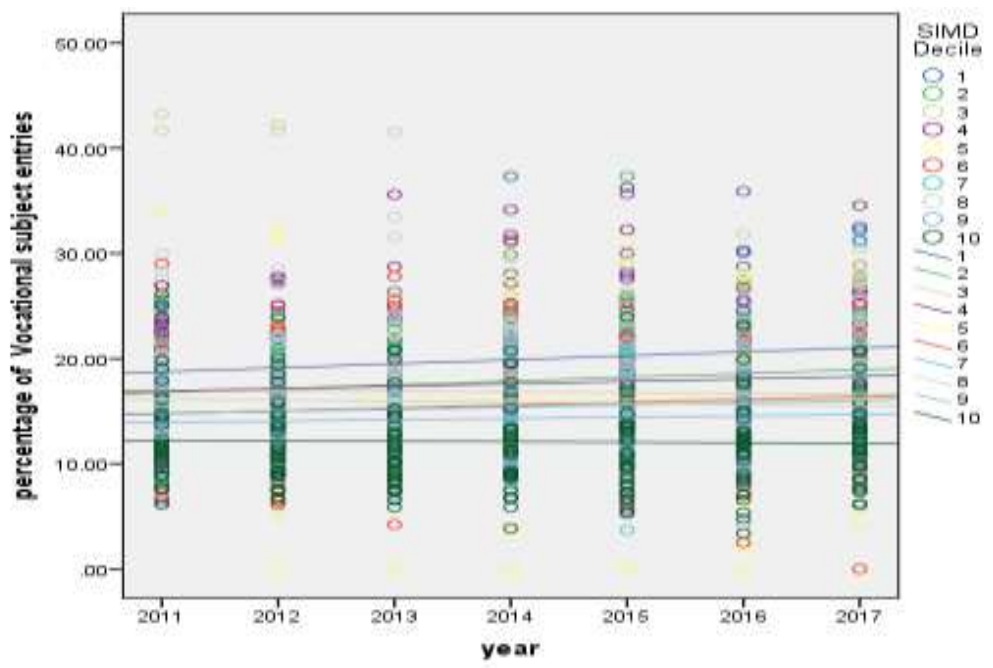




\section{Figure 7.}

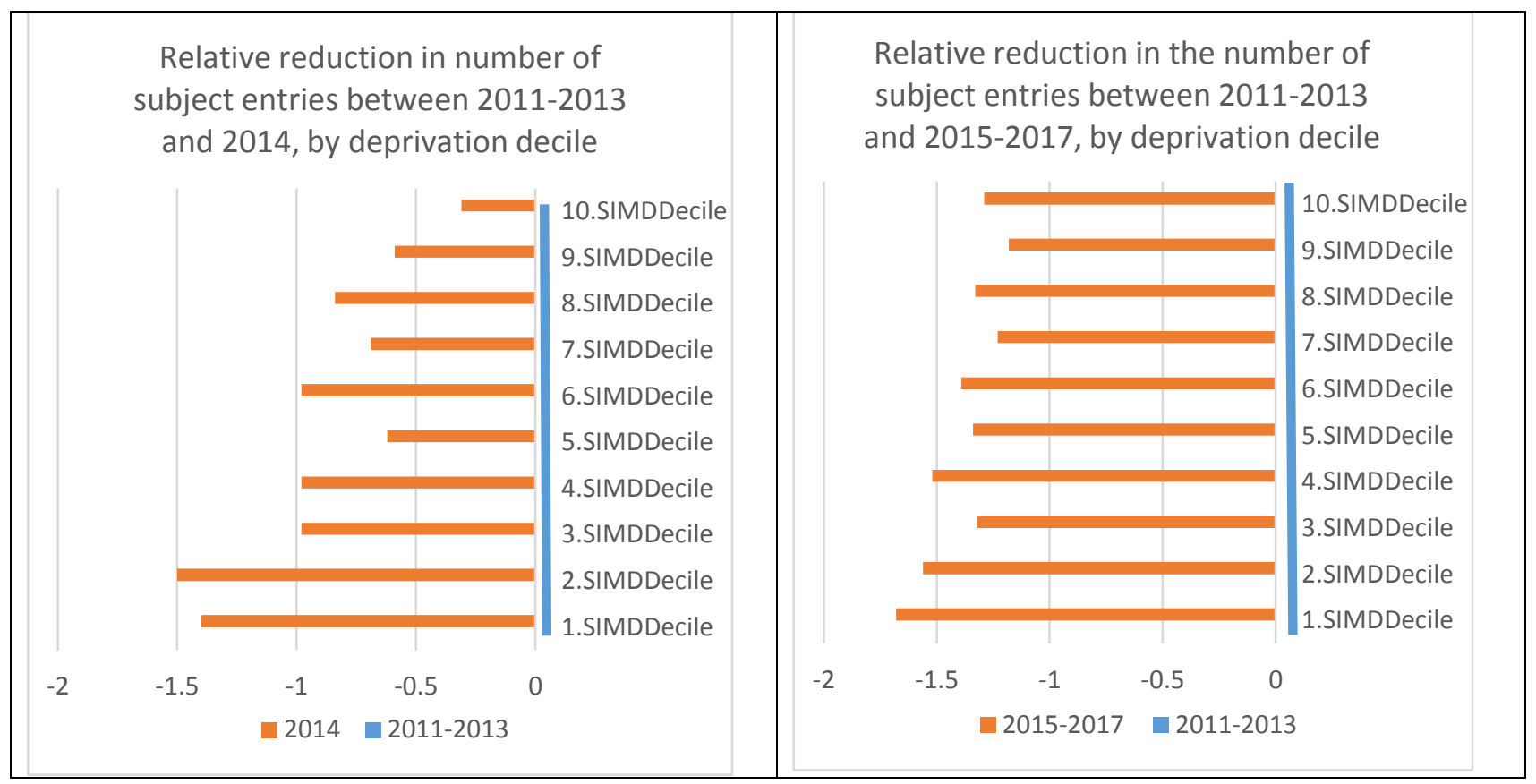

